\title{
Luminescent and Photoconductive Layered Lead Halide Perovskite Compounds Comprising Mixtures of Cesium and Guanidinium Cations
}

\author{
Olga Nazarenko, ${ }^{\dagger,+, \S}$ Martin Robert Kotyrba, ${ }^{\dagger, \ddagger, \S}$ Michael Wörle, ${ }^{\dagger}$ Eduardo Cuervo-Reyes, ${ }^{\dagger}$ \\ Sergii Yakunin, ${ }^{\dagger, \ddagger 0}$ and Maksym V. Kovalenko*, ${ }^{*}, \ddagger$ (이 \\ ${ }^{\dagger}$ ETH Zürich, Department of Chemistry and Applied Biosciences, CH-8093 Zurich, Switzerland \\ ${ }^{\ddagger}$ Empa-Swiss Federal Laboratories for Materials Science and Technology, CH-8600 Dübendorf, Switzerland \\ Supporting Information
}

ABSTRACT: Interest in hybrid organic-inorganic lead halide compounds with perovskite-like two-dimensional crystal structures is growing due to the unique electronic and optoelectronic properties of these compounds. Herein, we demonstrate the synthesis, thermal and optical properties, and calculations of the electronic band structures for one- and twolayer compounds comprising both cesium and guanidinium cations: $\mathrm{Cs}\left[\mathrm{C}\left(\mathrm{NH}_{2}\right)_{3}\right] \mathrm{PbI}_{4}$ (I), $\mathrm{Cs}\left[\mathrm{C}\left(\mathrm{NH}_{2}\right)_{3}\right] \mathrm{PbBr}_{4}$ (II), and $\mathrm{Cs}_{2}\left[\mathrm{C}\left(\mathrm{NH}_{2}\right)_{3}\right] \mathrm{Pb}_{2} \mathrm{Br}_{7}$ (III). Compounds I and II exhibit intense photoluminescence at low temperatures, whereas compound III is emissive at room temperature. All of the obtained substances are stable in air and do not thermally decompose until $300{ }^{\circ} \mathrm{C}$. Since $\mathrm{Cs}^{+}$and $\mathrm{C}\left(\mathrm{NH}_{2}\right)_{3}{ }^{+}$are increasingly utilized in precursor solutions for depositing polycrystalline lead halide perovskite thin films for photovoltaics, exploring possible compounds within this compositional space is of high practical relevance to understanding the photophysics and atomistic chemical nature of such films.

\section{INTRODUCTION}

Organic-inorganic layered lead halide compounds with perovskite-like structures are widely studied due to their fascinating electronic and optical properties and their rich structural chemistry. ${ }^{1-21}$ Fundamental to the construction of perovskites is the formation of $\mathrm{PbX}_{6}$ octahedra $\left(\mathrm{X}=\mathrm{Cl}^{-}, \mathrm{Br}^{-}\right.$, $\mathrm{I}^{-}$and mixtures thereof) and their condensation into crystals that possess two- or three-dimensional $(2 \mathrm{D}$ and $3 \mathrm{D}$, respectively) corner sharing. Such extended 2D and 3D delocalization of electronic bands imparts semiconductive properties. Compounds with $3 \mathrm{D}$ arrangements and the generic formula of $\mathrm{APbX}_{3}$ are formed when very small A-site cations are utilized $\left(\mathrm{A}^{+}=\mathrm{Cs}^{+}, \mathrm{CH}_{3} \mathrm{NH}_{3}{ }^{+}, \mathrm{CH}\left(\mathrm{NH}_{2}\right)_{2}{ }^{+}\right) .{ }^{22-29}$ In contrast, larger A-site cations do not fit within the highly confined space between the octahedra. When a larger A-site organic cation is employed, the most likely outcome is the formation of $2 \mathrm{D}$ compounds, such as the compounds with the generic formula $\mathrm{A}_{2} \mathrm{PbX}_{4}$ consisting of single layers of $\mathrm{PbX}_{6}$ octahedra sharing four of their corners, with the A cations in the interlayer space. Most of the known layered (2D) perovskite derivatives have mono- or diammonium cations, i.e., $\left(\mathrm{RNH}_{3}\right)_{2} \mathrm{MX}_{4}$ and $\left(\mathrm{NH}_{3} \mathrm{RNH}_{3}\right) \mathrm{PbX}_{4}$, respectively, where $\mathrm{R}$ is commonly an alkyl chain. The nonspherical geometry of $\mathrm{RNH}_{3}{ }^{+}$cations plays a significant role in the crystal symmetry of $\left(\mathrm{RNH}_{3}\right)_{2} \mathrm{MX}_{4}$ compounds, in addition to distortions and tilting of the $\mathrm{PbX}_{6}$ octahedra, which are often caused by Jahn-Teller and/or



lone-pair effects. ${ }^{30-33}$ The orientation of the alkylammonium cations between the inorganic layers allows the ammonium groups $\left(-\mathrm{NH}_{3}\right)$ to form hydrogen bonds with neighboring halogen ions.

These $\mathrm{A}_{2} \mathrm{PbX}_{4}$ compounds can therefore be considered strongly quantum confined systems, i.e., quantum wells, wherein electron motion is limited to two dimensions. An interlayer organic entity acts as the potential wall. The variation in the carbon chain length in $\left(\mathrm{RNH}_{3}\right)_{2} \mathrm{PbI}_{4}$ (from 4 to 14 carbon atoms) has a rather modest effect on the observed band gap energies. For example, the energies of the photoluminescence (PL) maxima are $2.35 \mathrm{eV}$ for $\mathrm{C} 4$ and $2.4 \mathrm{eV}$ for C10, confirming a highly localized quantum-well-like behavior. ${ }^{4,5,31}$ Engineering the chemistry of these compounds at the interlayer space is of increasing interest, ${ }^{18}$ with examples including intercalations of molecules such as hexane, dichlorobenzene, iodine, etc. $^{34,35}$ However, engineering the inorganic slab remains the principal approach to adjusting the absorption edges and PL maxima. For example, band gaps of 3.75, 3.17, and $2.55 \mathrm{eV}$ are found for $\mathrm{X}^{-}=\mathrm{Cl}^{-}, \mathrm{Br}^{-}, \mathrm{I}^{-}$, respectively, in $\left(\mathrm{C}_{10} \mathrm{H}_{21} \mathrm{NH}_{3}\right)_{2} \mathrm{PbX}_{4}{ }^{36}$

Another strategy to tune the electronic structure is to increase the thickness of the lead halide slabs from a single layer to multiple layers, thereby tuning the band gap energies between

Received: May 15, 2017

Published: September 12, 2017 
the two limiting cases of $2 \mathrm{D}_{2} \mathrm{PbX}_{4}$ and $3 \mathrm{D} \mathrm{APbX}_{3}$. Creating thicker slabs must involve at least two A-site cations, wherein the larger cation remains as an interlayer cation and the second cation fills in the smaller interslab cavities (which are of similar size as in the limiting case of $\mathrm{APbX}_{3}$ compounds). Structurally, these compounds are analogues to the Ruddlesden-Popper phase, as in the case of $\left(\mathrm{RNH}_{3}\right)_{2}\left(\mathrm{CH}_{3} \mathrm{NH}_{3}\right)_{n-1} \mathrm{~Pb}_{n} \mathrm{X}_{3 n+1}(\mathrm{R}=$ $\left.\mathrm{C}_{9} \mathrm{H}_{19}-, \mathrm{Ph}-\mathrm{CH}_{2} \mathrm{CH}_{2}-; \mathrm{X}^{-}=\mathrm{Br}^{-}, \mathrm{I}^{-}\right) .{ }^{37}$ Herein, a small $\mathrm{CH}_{3} \mathrm{NH}_{3}{ }^{+}$fills voids within the lead halide slabs, and the long alkyl chain ammonium ions are situated between the slabs, thus determining the interslab distance and defining the crystallographic orientation of the perovskite sheets. These phases can be seen as $2 \mathrm{D}$ slices of a $3 \mathrm{D} \mathrm{APbX}_{3}$ structure with various crystallographic orientations. For further crystallographic details of such compounds, we refer readers to recent review and research articles. ${ }^{7,38,39}$

In $\left(\mathrm{C}_{4} \mathrm{H}_{9} \mathrm{NH}_{3}\right)_{2}\left(\mathrm{CH}_{3} \mathrm{NH}_{3}\right)_{n-1} \mathrm{~Pb}_{n} \mathrm{I}_{3 n+1}$, the band gap energies change from 2.43 to $1.91 \mathrm{eV}$ as the thickness is adjusted from $n=1$ to $n=4 .^{5}$ Due to such tunability, these $2 \mathrm{D}$ systems are presently being intensively investigated for their optical properties and applications in light emission and in solar cells. $1,431,40-42$ In particular, the archetypical 3D compound $\mathrm{CH}_{3} \mathrm{NH}_{3} \mathrm{PbI}_{3}(n=\infty)$ had been reported recently as an outstanding photovoltaic material with power conversion efficiencies repeatedly exceeding $20 \% .^{28,43-45}$ However, $\mathrm{CH}_{3} \mathrm{NH}_{3} \mathrm{PbI}_{3}$ is known to undergo irreversible degradation due to the volatile nature of the decomposition products (methylamine, hydrogen iodide (HI), etc.), which is accelerated upon exposure to moisture, as in ambient air. ${ }^{46}$ Higher chemical stability can be found within the family of $(\mathrm{PEA})_{2}\left(\mathrm{CH}_{3} \mathrm{NH}_{3}\right)_{n-1} \mathrm{~Pb}_{n} \mathrm{I}_{3 n+1}$ (PEA = $\left.\mathrm{C}_{6} \mathrm{H}_{5}\left(\mathrm{CH}_{2}\right)_{2} \mathrm{NH}_{3}^{+}\right)$, wherein compounds with $n=1-3$ have been synthesized and characterized in detail. ${ }^{47,48}(\mathrm{PEA})_{2}\left(\mathrm{CH}_{3}-\right.$ $\left.\mathrm{NH}_{3}\right)_{2} \mathrm{~Pb}_{3} \mathrm{I}_{10}(n=3$, band gap of $2.1 \mathrm{eV})$ exhibits higher chemical stability than $\mathrm{CH}_{3} \mathrm{NH}_{3} \mathrm{PbI}_{3}$. ${ }^{48}$ The relevance of such structural motifs extends beyond lead-based halides; for example, in the tin iodide compounds $\left(\mathrm{C}_{4} \mathrm{H}_{9} \mathrm{NH}_{3}\right)_{2}\left(\mathrm{CH}_{3} \mathrm{NH}_{3}\right)_{n-1} \mathrm{Sn}_{n} \mathrm{I}_{3 n+1}$, for $n>3$ metallic behavior is observed, while compounds with $n<3$ are semiconductors. ${ }^{40}$ However, tin-based compounds are highly prone to oxidation to $\mathrm{Sn}^{4+}$, limiting their practical utility.

In this work, we aimed to fully eliminate protonated ammonium salts, such as those in primary, secondary, or ternary alkylamines, from the construction of layered lead halide perovskites. To create monolayer $\mathrm{A}_{2} \mathrm{PbX}_{4}$-like compounds, we replaced the unstable $\mathrm{CH}_{3} \mathrm{NH}_{3}{ }^{+}$with a mixture of $\mathrm{Cs}^{+}$and guanidinium $\left[\mathrm{C}\left(\mathrm{NH}_{2}\right)_{3}\right]^{+}$ions. Guanidinium is an ideal alternative to the primary ammonium ions due to its thermodynamic stability, high basicity $\left(\mathrm{p} K_{\mathrm{a}}=13.6\right)$, and strong hydrogenbonding capabilities. ${ }^{49,50}$ The high basicity of the guanidine molecule can be understood by considering a resonance stabilization of the guanidinium ion by $6-8 \mathrm{kcal} / \mathrm{mol}{ }^{51}$ The guanidinium cation has been previously incorporated into a variety of perovskite-like salts with the formate $\left(\mathrm{HCOO}^{-}\right)$ anion, $\left[\mathrm{C}\left(\mathrm{NH}_{2}\right)_{3}\right]\left[\mathrm{M}^{\mathrm{II}}(\mathrm{HCOO})_{3}\right]$, where $\mathrm{M}$ is $\mathrm{Mn}, \mathrm{Co}, \mathrm{Fe}, \mathrm{Ni}$, $\mathrm{Cu}, \mathrm{Zn}$, or $\mathrm{Cd}^{52,53}$ This suggests that guanidinium facilitates stable, highly symmetric structures. Although stable $\left[\mathrm{C}\left(\mathrm{NH}_{2}\right)_{3}\right]_{2}-$ $\mathrm{Pb}(\mathrm{Sn}) \mathrm{I}_{4}$ compounds have already been reported (with corrugated structure), ${ }^{54,55}$ our interest was to test three further possibilities: (i) whether it is possible to mix such a stable organic cation with an inorganic cation at the interlayer and what structural effects accompany this combination, (ii) whether this mixture can also enable the formation of slabs thicker than one monolayer, and (iii) whether a noncorrugated structure can form. The small Cs ion is universally suited both for interlayer locations and for filling the voids within the slab. In contrast, the guanidinium ion can be accommodated only in the interlayer space, despite being only slightly larger than $\mathrm{CH}_{3} \mathrm{NH}_{3}{ }^{+}$ and $\mathrm{CH}\left(\mathrm{NH}_{2}\right)_{2}{ }^{+}$.

We succeeded in obtaining three layered perovskite compounds with $n=1,2, \mathrm{Cs}\left[\mathrm{C}\left(\mathrm{NH}_{2}\right)_{3}\right] \mathrm{PbI}_{4}(\mathrm{I}), \mathrm{Cs}\left[\mathrm{C}\left(\mathrm{NH}_{2}\right)_{3}\right]$ $\mathrm{PbBr}_{4}$ (II), and $\mathrm{Cs}_{2}\left[\mathrm{C}\left(\mathrm{NH}_{2}\right)_{3}\right] \mathrm{Pb}_{2} \mathrm{Br}_{7}$ (III), all of which contain (2D) slabs of corner-sharing octahedra and possess satisfactory thermal stability (up to $300{ }^{\circ} \mathrm{C}$ ). Compounds I and II are luminescent upon moderate cooling, and compound III is emissive at room temperature. Photoresponsivities in the range of $1-10 \mathrm{~mA} \mathrm{~W}^{-1}$ and with narrow-band characteristics were measured for compounds I and III, confirming their extended semiconductor nature.

\section{METHODS}

Chemicals, Reagents, and Synthesis Procedures. Lead(II) iodide $\left(\mathrm{PbI}_{2}, 99 \%\right)$ and cesium bromide ( $\left.\mathrm{CsBr}, 99.9 \%\right)$ were purchased from Sigma-Aldrich. Lead(II) bromide $\left(\mathrm{PbBr}_{2}, 98+\%\right)$, hydrobromic acid ( $\mathrm{HBr}, 48 \%$ water solution), and guanidinium carbonate $(99+\%)$ were purchased from Acros. Cesium iodide (CsI, 99.9\%) and hydriodic acid (HI, 57\%, stabilized with $1.5 \%$ hypophosphorous acid, $\mathrm{H}_{3} \mathrm{PO}_{2}$ ) were received from ABCR. Diethyl ether $(>99 \%)$ was dried over molecular sieves. All chemicals were used as received without further purification.

$\mathrm{Cs}\left[\mathrm{C}\left(\mathrm{NH}_{2}\right)_{3}\right] \mathrm{PbI}_{4}$ (I), $\mathrm{Cs}\left[\mathrm{C}\left(\mathrm{NH}_{2}\right)_{3}\right] \mathrm{PbBr}_{4}$ (II), and $\mathrm{Cs}_{2}$ $\left[\mathrm{C}\left(\mathrm{NH}_{2}\right)_{3}\right] \mathrm{Pb}_{2} \mathrm{Br}_{7}$ (III) were synthesized from concentrated hydriodic and hydrobromic acids. The compounds were yellow (II, III) and red (I) microcrystalline powders (Figure S1 in the Supporting Information). A large excess ( $\geq 6$-fold) of guanidinium ions was found to be necessary to obtain the desired compounds.

$\mathrm{Cs}\left[\mathrm{C}\left(\mathrm{NH}_{2}\right)_{3}\right] \mathrm{Pbl}_{4}(\mathrm{I}) . \mathrm{CsI}(1.55 \mathrm{mmol}),\left[\mathrm{C}\left(\mathrm{NH}_{2}\right)_{3}\right]_{2} \mathrm{CO}_{3}(6 \mathrm{mmol})$, and $\mathrm{PbI}_{2}(1.55 \mathrm{mmol})$ were loaded into a $25 \mathrm{~mL}$ round- bottom flask, and $10 \mathrm{~mL}$ of $\mathrm{HI}$ acid (57\% in water) was added carefully. Strong gas evolution was observed, and a red precipitate immediately formed. The precipitate was redissolved upon heating in a glycerol bath, yielding a clear yellow solution. Next, the flask was cooled under a cold water stream, causing the formation of a red crystalline precipitate of $\mathbf{I}$. The solution remained undisturbed for another few hours to allow further precipitation. The precipitate was separated by vacuum filtration, washed with diethyl ether, and dried in a vacuum oven at $60{ }^{\circ} \mathrm{C}$. A yield of $72 \%$ was estimated relative to $\mathrm{Pb}$. To obtain larger crystals of $\mathbf{I}$ for photoconductivity measurements $\left(0.5-2 \mathrm{~mm}^{3}\right)$, the precursor solution was slowly evaporated at $60{ }^{\circ} \mathrm{C}$ instead of cooling.

$\mathrm{Cs}\left[\mathrm{C}\left(\mathrm{NH}_{2}\right)_{3}\right] \mathrm{PbBr}_{4}$ (II). $\mathrm{CsBr}(2 \mathrm{mmol}),\left[\mathrm{C}\left(\mathrm{NH}_{2}\right)_{3}\right]_{2} \mathrm{CO}_{3}(6 \mathrm{mmol})$, and $\mathrm{PbBr}_{2}(2 \mathrm{mmol})$ were loaded into a $25 \mathrm{~mL}$ round- bottom flask, and $10 \mathrm{~mL}$ of $\mathrm{HBr}(48 \%)$ acid was carefully added. Strong gas evolution was observed, and a yellow precipitate formed. Subsequent manipulations of the solution were identical with the procedure for compound I. A yield of $63 \%$ was estimated relative to $\mathrm{Pb}$.

$\mathrm{Cs}_{2}\left[\mathrm{C}\left(\mathrm{NH}_{2}\right)_{3}\right] \mathrm{Pb}_{2} \mathrm{Br}_{7}$ (III). $\mathrm{CsBr}(1 \mathrm{mmol}),\left[\mathrm{C}\left(\mathrm{NH}_{2}\right)_{3}\right]_{2} \mathrm{CO}_{3}(3 \mathrm{mmol})$, and $\mathrm{PbBr}_{2}(2 \mathrm{mmol})$ were used for this synthesis. Upon addition of $12 \mathrm{~mL}$ of $\mathrm{HBr}(48 \%)$ acid, strong gas evolution was observed, and a yellow precipitate formed. Subsequent manipulations for the solution were identical with the procedure for compound I. A yield of $27 \%$ was estimated relative to $\mathrm{Pb}$. To obtain larger crystals of III for photoconductivity measurements $\left(0.5-2 \mathrm{~mm}^{3}\right)$, the precursor solution was slowly evaporated at $60{ }^{\circ} \mathrm{C}$.

$\left(n-\mathrm{C}_{4} \mathrm{H}_{9} \mathrm{NH}_{3}\right)_{2} \mathrm{Pbl}_{4}$ (IV). This compound was prepared according to Stoumpous et al.

$\left[\mathrm{C}\left(\mathrm{NH}_{2}\right)_{3}\right]_{2} \mathrm{Pbl}_{4}(\mathrm{~V})$. This compound was obtained as yellow platelets from a hot acidic solution using $\left[\mathrm{C}\left(\mathrm{NH}_{2}\right)_{3}\right]_{2} \mathrm{CO}_{3}(3 \mathrm{mmol}), \mathrm{PbI}_{2}$ ( $2 \mathrm{mmol}$ ) and $7.5 \mathrm{~mL}$ of $\mathrm{HI}(57 \%)$. The crystals were separated by vacuum filtration, washed with diethyl ether and dried in a vacuum oven at $60{ }^{\circ} \mathrm{C}$.

$\mathrm{CsPbBr}_{3}$ (VI). This compound was crystallized from aqueous $\mathrm{HBr}$ using the corresponding bromides in stoichiometric quantities $(0.15 \mathrm{M}$ $\mathrm{PbBr}_{2}, 0.15 \mathrm{M} \mathrm{CsBr}$ ). Upon cooling to room temperature, orange 
a

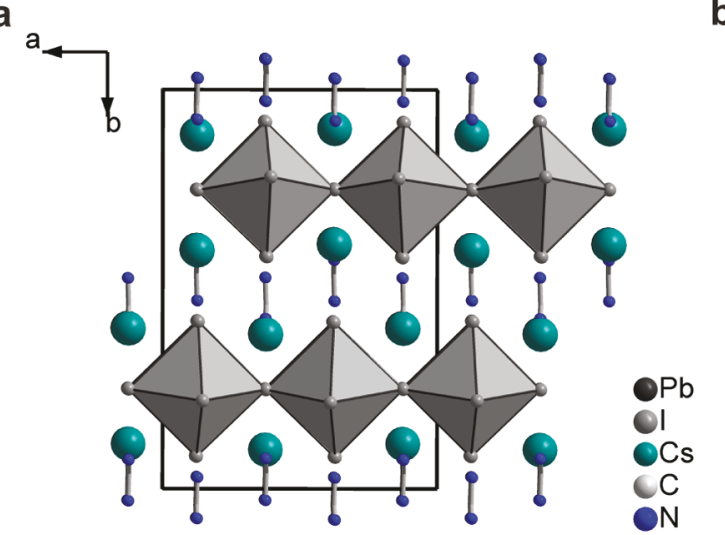

b

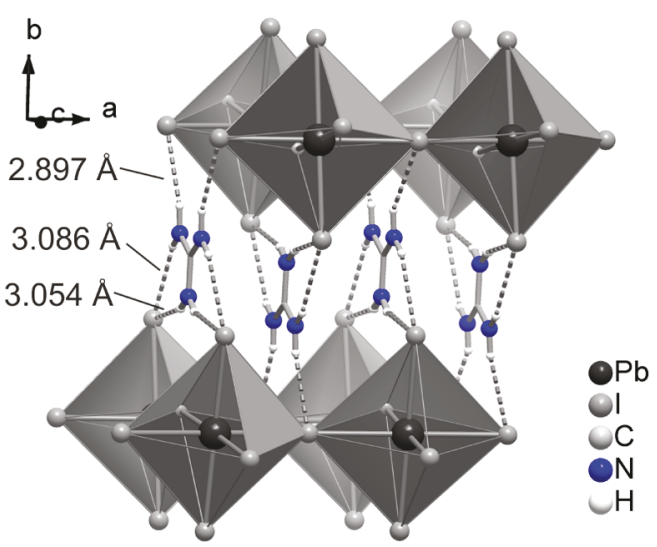

c



$\vec{b}$

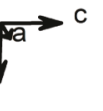

\section{8}

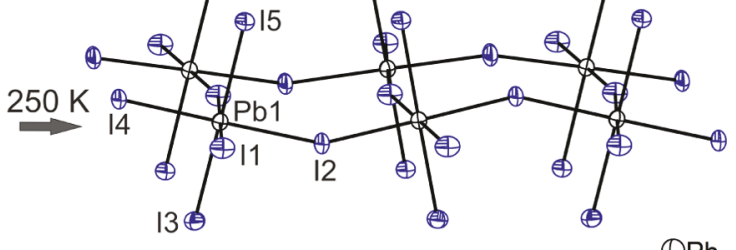

(日)

Figure 1. (a) Crystal structure of $2 \mathrm{D} \mathrm{Cs}\left[\mathrm{C}\left(\mathrm{NH}_{2}\right)_{3}\right] \mathrm{PbI}_{4}$ (I). (b) Hydrogen bonding between protons of guanidinium cations and iodine atoms of two $2 \mathrm{D} \mathrm{Pb}-\mathrm{I}$ layers. (c) Distorted $\mathrm{Pb}-\mathrm{I}$ octahedral coordination.

crystals precipitated. Subsequent manipulations of the solution were identical with the procedure for compound $\mathbf{I}$.

$\left(\mathrm{n}-\mathrm{C}_{4} \mathrm{H}_{9} \mathrm{NH}_{3}\right)_{2} \mathrm{PbBr}_{4}$ (VII). The synthesis of VII from hydrobromic acid was analogous to that of $\mathbf{I V}$, using $n$-butylamine and $\mathrm{PbO}$ (in stoichiometric quantities, $0.5 \mathrm{M} \mathrm{PbO}, 1 \mathrm{M} \mathrm{C}_{4} \mathrm{H}_{9} \mathrm{NH}_{2}$ ). Upon cooling to room temperature, colorless transparent plates crystallized. Subsequent manipulations of the solution were identical with the procedure for compound $\mathbf{I}$.

$\mathrm{CsPb}_{2} \mathrm{Br}_{5}$ (VIII). This compound was crystallized from stoichiometric quantities of the corresponding bromides in hydrobromic acid. Typically, $\mathrm{CsBr}(0.7 \mathrm{mmol})$ and $\mathrm{PbBr}_{2}(1.4 \mathrm{mmol})$ were dissolved in $6 \mathrm{~mL}$ of hot $\mathrm{HBr}$ acid. Upon cooling to room temperature, colorless crystalline plates precipitated, followed by vacuum filtration, washing with diethyl ether, and drying in the vacuum oven at $60{ }^{\circ} \mathrm{C}$.

$\left[\mathrm{C}\left(\mathrm{NH}_{2}\right)_{3}\right]_{2} \mathrm{PbBr}_{4}$ (IX). This compound was grown from a hot acid solution. $\left[\mathrm{C}\left(\mathrm{NH}_{2}\right)_{3}\right]_{2} \mathrm{CO}_{3}(4 \mathrm{mmol})$ and $\mathrm{PbBr}_{2}(4 \mathrm{mmol})$ were loaded into a $25 \mathrm{~mL}$ round-bottom flask with $10 \mathrm{~mL}$ of $\mathrm{HBr}(48 \%)$ acid. The precipitate was redissolved upon heating in a glycerol bath, yielding a yellowish solution. Upon cooling to room temperature, colorless transparent crystals appeared within a few hours.

$\mathrm{CsPbl}_{3}(\mathrm{X})$. This compound was crystallized in the form of orange needles from $\mathrm{HI}$ acid using the corresponding iodides in stoichiometric quantities as precursors $\left(0.1 \mathrm{M} \mathrm{PbI}_{2}, 0.1 \mathrm{M} \mathrm{CsI}\right)$.

Characterization. Powder X-ray diffraction (XRD) patterns were collected in the transmission mode (Debye-Scherrer geometry) using a STADI P diffractometer (STOE\& Cie $\mathrm{GmbH}$ ) equipped with a silicon strip MYTHEN 1K Detector (Fa. DECTRIS) with a curved $\mathrm{Ge}(111)$ monochromator $\left(\mathrm{Cu} \mathrm{K} \alpha_{1}=1.54056 \AA\right)$. Single-crystal XRD measurements were conducted using a Bruker Smart Platform diffractometer equipped with an Apex I CCD detector and a molybdenum (Mo K $\alpha=0.71073 \AA$ ) sealed tube as an X-ray source. The crystals were tip-mounted on a micromount with paraffin oil. The data were processed using APEX3 (Bruker software), and the structure solution and refinement were performed with SHELXT and SHELXL programs embedded in the Olex 2 software package. For twin indexing, the cell_now algorithm (a part of the Bruker APEX2 software package) ${ }^{-}$was used (see the crystallographic data section in the
Supporting Information). The obtained crystal structures of I, II, III and $\mathbf{I}^{\prime}$ were deposited as CIF files into the CCDC database with the numbers 1552605 (I), 1552602 (III), 1552603 (II), and $1552604\left(\mathbf{I}^{\prime}\right)$. UV-vis absorbance spectra of the microcrystalline powders were collected using a Jasco V670 spectrophotometer equipped with deuterium (190-350 nm) and halogen (330-2700 nm) lamps and an integrating sphere (ILN-725, working wavelength range of 220-2200 $\mathrm{nm})$.

The absorbance spectra were estimated from reflectance and transmittance spectra collected from a thin layer of powder dispersed in an optically transparent Teflon grease and by diffuse reflectance transformed into absorbance using the Kubelka-Munk relation. The band gaps were estimated from the Kubelka-Munk function $\left(F\left(R_{\infty}\right)\right)$, by subtracting excitonic peaks from the absorption edge. First, the excitonic transition was fitted with the Gaussian function. The residual spectrum was used to calculate $\left[F\left(R_{\infty}\right) \cdot h \nu\right]^{2}$ (where $h \nu$ is the incident photon energy). Plotting $\left[F\left(R_{\infty}\right) \cdot h \nu\right]^{2}$ versus energy $(h \nu)$ gave a spectrum for estimation of band gaps. Although the fitting with a Gaussian function does not give an impeccable fit for the sub band gap region of the Urbach tail, this fit gives the possibility of estimating the band gap values. A better understanding of the spectral region at the Urbach tail can be attained by modeling according to the Elliott approach. ${ }^{57,58}$ PL spectra were measured in a Joule-Thomson cryostat (MMR Technologies) operated in the temperature range of $78-300 \mathrm{~K}$. PL emission was recorded with a heating rate of approximately $5 \mathrm{~K} / \mathrm{min}$. A $355 \mathrm{~nm}$ excitation source (a frequency-tripled, picosecond Nd:YAG laser, the Duetto model from Time-Bandwidth) and a CW diode laser with an excitation wavelength of $405 \mathrm{~nm}$ were used. Scattered laser emission was filtered out using dielectric long-pass filters with edges at 400 and $450 \mathrm{~nm}$, respectively. The emission from the samples was collimated to an optical fiber and recorded at $1 \mathrm{~K}$ intervals with an SP-2300 spectrograph from Princeton Instruments coupled with a CCD array (LC100/M from Thorlabs). PL spectra were corrected to the spectral sensitivity of the setup using Planck irradiation from a calibrated halogen lamp. Time-resolved photoluminescence (TR-PL) measurements were performed using a time-correlated single photon counting (TCSPC) setup, equipped with a SPC-130-EM counting module 


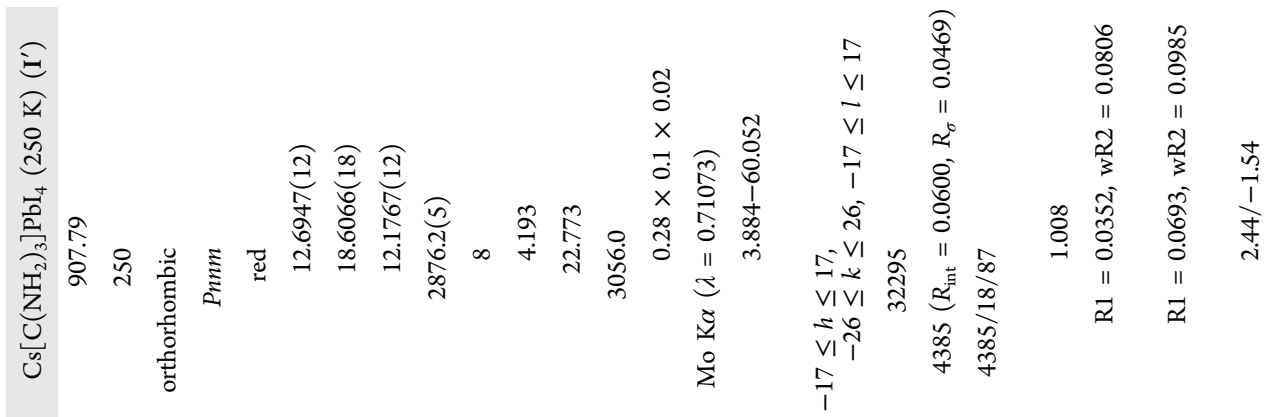

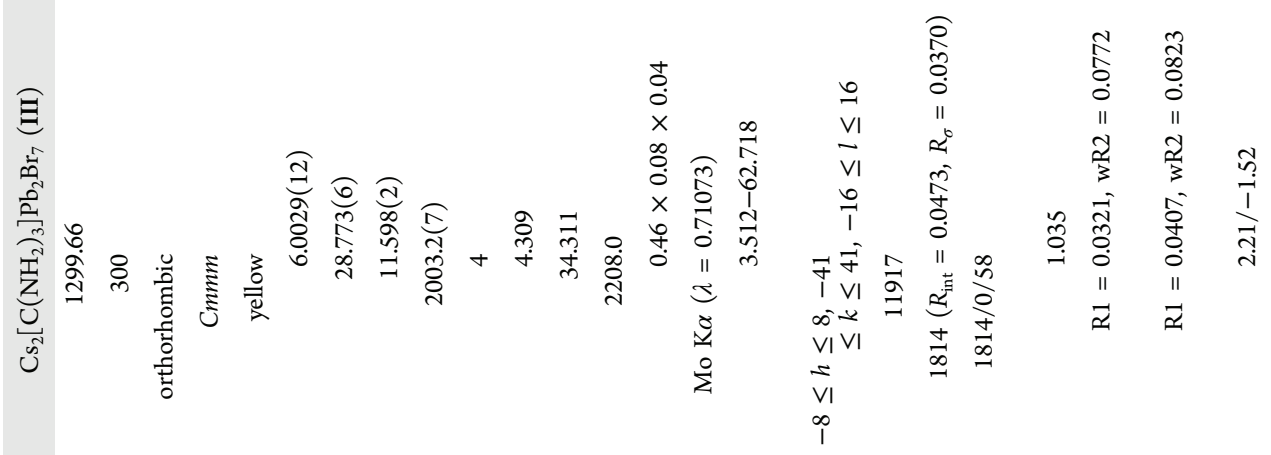

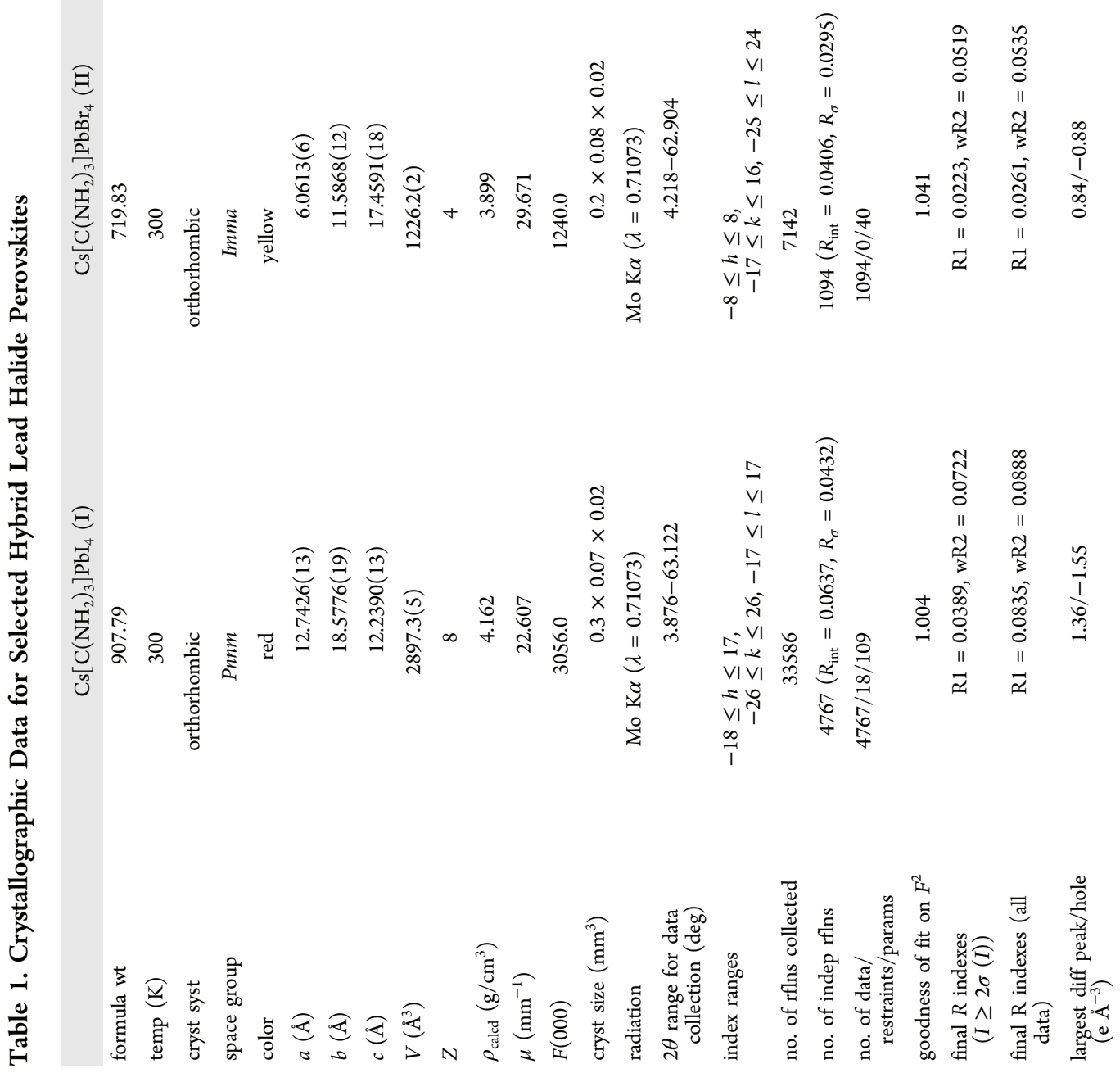


a



C

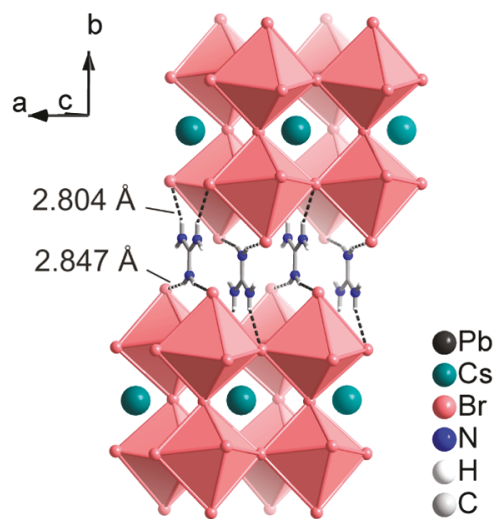

b



d

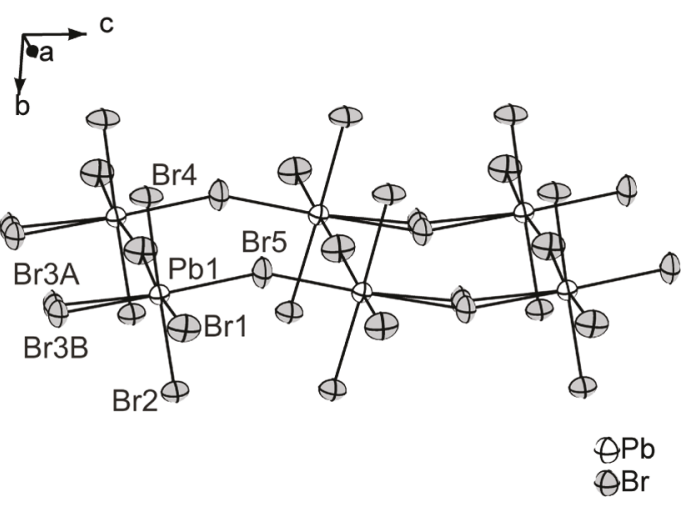

Figure 2. (a, b) Crystal structures of $2 \mathrm{D} \mathrm{Cs}\left[\mathrm{C}\left(\mathrm{NH}_{2}\right)_{3}\right] \mathrm{PbBr}_{4}$ (II) and $\mathrm{Cs}_{2}\left[\mathrm{C}\left(\mathrm{NH}_{2}\right)_{3}\right] \mathrm{Pb}_{2} \mathrm{Br}_{7}$ (III) perovskites. (c) Hydrogen-halogen bonds between protons of guanidinium cations and bromides of $2 \mathrm{D}$ layers of $\mathrm{Cs}_{2}\left[\mathrm{C}\left(\mathrm{NH}_{2}\right)_{3}\right] \mathrm{Pb}_{2} \mathrm{Br}_{7}$. (d) Distortion of $\mathrm{Pb}-\mathrm{Br}$ octahedral coordination in III and bromide split position in the crystal structure of $\mathrm{Cs}_{2}\left[\mathrm{C}\left(\mathrm{NH}_{2}\right)_{3}\right] \mathrm{Pb}_{2} \mathrm{Br}_{7}$.

(Becker \& Hickl GmbH) and an IDQ-ID-100-20-ULN avalanche photodiode (Quantique) for recording the decay traces. The emission was excited by a frequency-tripled $(\lambda 355 \mathrm{~nm})$, picosecond $\mathrm{Nd}$ :YAG laser, the Duetto model from Time-Bandwidth, externally triggered at a $78 \mathrm{kHz}$ repetition rate. PL emission from the samples passed through sets of long- and short-pass optical filters selecting the wavelength ranges 500-600 and 650-800 $\mathrm{nm}$. Thermal analysis (thermogravimetry, TG, and differential thermal analysis, DTA) was performed using a NETZSCH STA $409 \mathrm{C} / \mathrm{CD}$ instrument in an alumina crucible under argon flow $(40 \mathrm{~mL} / \mathrm{min})$ with a heating rate of $10 \mathrm{~K} / \mathrm{min}$.

Photoconductivity. Measurements were performed with illumination from a tungsten lamp dispersed by an Acton SP2150 (Roper Scientific) spectrograph/monochromator. The light was modulated by a mechanical chopper at a frequency of $13 \mathrm{~Hz}$. The sample was gently pressed from two opposite sides by conductive rubber contacts in a custom-made holder and biased at $50 \mathrm{~V}$ through these contacts using a Keithley 236 SMU apparatus. The bias voltage was adjusted to obtain stable dark currents in the range of 1-10 nA. The signal, amplitude, and phase were measured across a series resistance by a Stanford Research 830 lock-in amplifier. The light intensity was controlled by a calibrated power detector (UM9B-BL, Gentec-EO). The current-voltage (I-V) characteristics were measured using a Keithley 236 SMU apparatus.

Electronic Structure Calculations. Two implementations of density functional theory (DFT) were employed. For the calculations of the band structure and density of states, we used the Dmol3 package within the Materials Studio suite. ${ }^{59,60}$ For the real space representation of the bonding, we computed the electron localization function $(\mathrm{ELF})^{61,62}$ using Savin's implementation within the TB-LMTO-ASA code developed at MPI Stuttgart. ${ }^{63}$ The ELF plots contain information on both ELF and electron density over a given plane and were obtained using a code developed in-house. ELF values and electron density values are shown as the color of the pixels and the number of colored pixels, respectively, over a black background. Scalarrelativistic corrections were included in all calculations because they are expected to play an important role in the presence of heavy elements. The LMTO is an all-electron method, and in Dmol3 we chose to also include all electrons equally in the scalar-relativistic calculation, meaning that no pseudopotential was used. Within Dmol3, the tolerance for self-consistency was set to about $10^{-6} \mathrm{Ha}$ for the total energy, using the number of $k$ points that results in a grid with separation smaller than $0.03 \AA^{-1}$ in reciprocal space. We employed the BOP (Becke one parameter) exchange-correlation functional, with which we have had in general better outcomes for the gaps in comparison with the commonly used PBE. For the LMTO calculations, we employed the Langreth-Mehl-Hu exchange-correlation functional. The self-consistency tolerance was set to $10^{-5} \mathrm{Ry}$ for the total energy and $10^{-5} \mathrm{e}$ for the atomic charges. Taking advantage of the speed of the LMTO code, the $k$ space was sampled over 64-time denser grids than those used within Dmol3. The investigation of the effects on the band gaps due to spin-orbit coupling and nonlocal exchange interactions, which require the extensive use of semiempirical methods, should be the subject of future (and more computationally oriented) works.

\section{RESULTS AND DISCUSSION}

Crystal Structures of I-III. The synthesized compounds were characterized by single-crystal XRD (Table 1 and Figures 1 and 2), powder XRD, thermal analysis (Figures 3), optical absorption, and PL spectroscopy (Figures 4 and 5). In addition, electronic structures were calculated by DFT methods. 


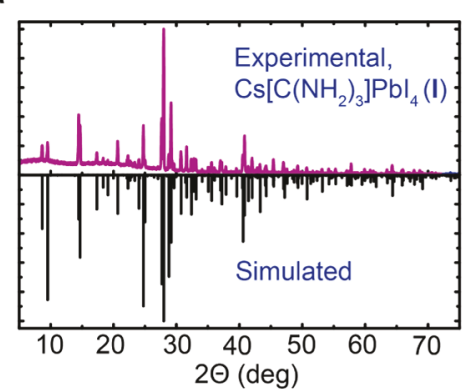

d

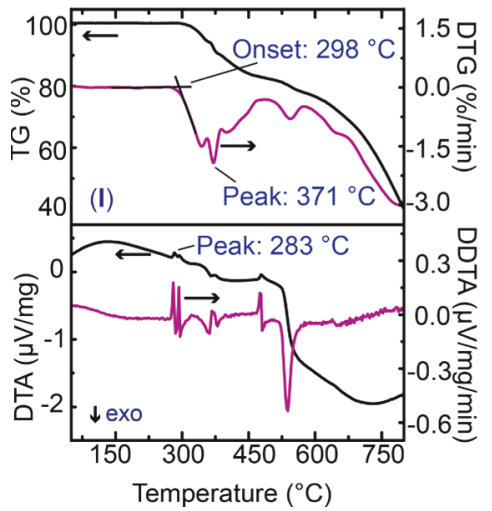



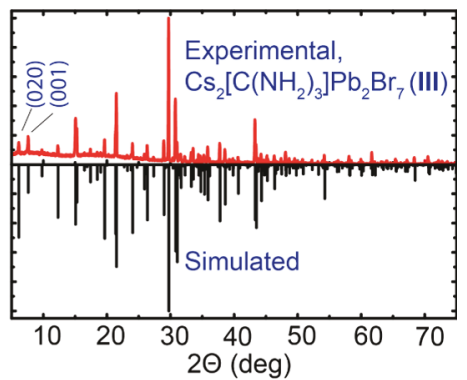

f

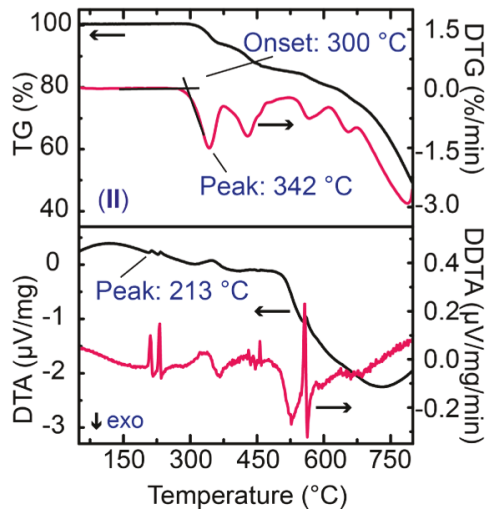

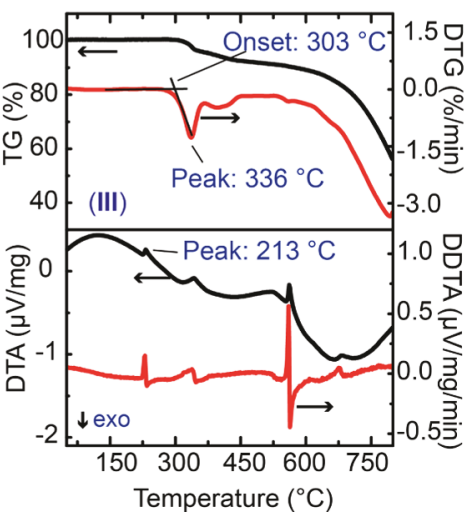

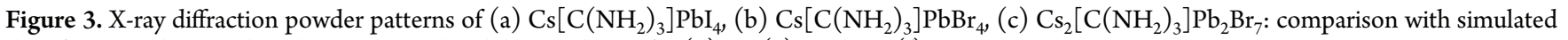
data from single-crystal analysis. Thermal stability analysis of I (d), II (e), and III (f).

The crystal structures were solved with direct methods; light elements $(\mathrm{C}, \mathrm{N})$ were located in the difference Fourier map, and hydrogen atoms were placed at calculated positions. Some of the crystals under investigation were twinned. Twin indexing and integration was performed with the Bruker Apex3 program software package. The compounds crystallize in the orthorhombic crystal system (centrosymmetric space groups Pnnm, Imma, and Cmmm for I-III, respectively; Table 1). The crystal structures of I and II feature single layers $(n=1)$ of $\mathrm{PbX}_{6}$ octahedra, whereas compound III consists of a bilayer arrangement of the octahedra (Figures 1 and 2). To obtain the compound with $n=2$, i.e., $\mathrm{Cs}_{2}\left[\mathrm{C}\left(\mathrm{NH}_{2}\right)_{3}\right] \mathrm{Pb}_{2} \mathrm{Br}_{7}$, the $\mathrm{Cs}: \mathrm{C}\left(\mathrm{NH}_{2}\right)_{3}: \mathrm{Pb}$ molar ratio was adjusted to $1: 6: 2$ during the synthesis. Further varying the molar ratios or thermal growth profiles during the crystallization did not yield compounds other than I-III. 2D layers were separated with a mixture of organic (guanidinium) and inorganic (cesium) cations in a 1:1 ratio, alternating in a periodic matter. As is typical for layered $\mathrm{A}_{2} \mathrm{BX}_{4}$ systems $(n=1)$, neighboring layers are shifted by half of the octahedra with respect to each other (Figure 1a), maximizing the $\mathrm{X}-\mathrm{X}$ distance for minimal electrostatic repulsion. ${ }^{64}$ In all three compounds, the $\mathrm{PbX}_{6}$ octahedra tilt, e.g., they deviate from the idealized $\mathrm{Pb}-\mathrm{X}-\mathrm{Pb}$ angle of $180^{\circ}$, to better accommodate the small $\mathrm{Cs}^{+}$and large $\mathrm{C}\left(\mathrm{NH}_{2}\right)_{3}{ }^{+}$cations. Guanidinium ions closely pack, with intermolecular $d(\mathrm{C} \cdots \mathrm{N})$ values in the range of 3-3.2 A for all three compounds (Table S1 in the Supporting Information), and form hydrogen-halogen bonds with neighboring halogen ions (bromine or iodine, Figures $1 \mathrm{~b}$ and $2 \mathrm{c}$ and Tables S5, S8, S11, S14, and S17 in the Supporting Information). $\mathrm{Cs}\left[\mathrm{C}\left(\mathrm{NH}_{2}\right)_{3}\right] \mathrm{PbI}_{4}$ (I, Figure 1) exhibits somewhat higher structural disorder and stronger distortions in comparison to those of its bromide analogue. Both bridging iodides (along the $c$ axis) of $\mathrm{PbI}_{6}$ octahedra can be represented as split into two positions (Figure $1 \mathrm{c}$ ). All $\mathrm{Pb}-\mathrm{I}$ bond lengths range from 3.101(2) to 3.226(1) $\AA$. The average $\mathrm{Pb}-\mathrm{I}$ distance is $3.168 \AA$, which is slightly longer than that in the cubic structure of $\mathrm{CsPbI}_{3}$, where $d(\mathrm{~Pb}-\mathrm{I})=3.1447 \AA$, ${ }^{65}$ but smaller than that in the closely related $\left(\mathrm{C}_{4} \mathrm{H}_{9} \mathrm{NH}_{3}\right)_{2} \mathrm{PbI}_{4}$, where $d(\mathrm{~Pb}-\mathrm{I})=3.184 \AA$ was estimated. ${ }^{31}$ Below $250 \mathrm{~K}$, the crystals of $\mathrm{I}$ undergo extensive cracking into multiple new domains, prohibiting structural description of the newly formed phase(s). However, at exactly $250 \mathrm{~K}$, crystal structure refinement is still possible, and certain conclusions can be drawn from the electron density map (this compound is denoted by $\mathbf{I}^{\prime}$ ). In particular, the disorder of the bridging iodides ( $c$ direction) is reduced, and they can be described by a single atomic position (Figure $1 c$ ). The $\mathrm{Pb}-\mathrm{I}$ distances in $\mathbf{I}^{\prime}$ are in the range of 3.145(1)-3.228(1) $\AA$.

Compound II is a $2 \mathrm{D}$ compound with $n=1$ (Figure 2a). Bridging bromides $(\mathrm{Br} 3)$ (along the $b$ direction) are disordered at two positions in the $\mathrm{Pb}-\mathrm{Br}$ octahedra (Figure $\mathrm{S} 2 \mathrm{a}$ in the Supporting Information). The distortion of the lead bromide octahedra could be described by $\mathrm{Pb}-\mathrm{Br} 3-\mathrm{Pb}$ angles, which are equal to $157.488(3)^{\circ}$. Two apical and two bridging (along the $a$ axis) bromides can be depicted as lying in the same plane with ideal $90^{\circ} \mathrm{Br}-\mathrm{Pb}-\mathrm{Br}^{\prime}$ angles: $d(\mathrm{~Pb}-\mathrm{Br} 1)=3.030(1) \AA$ and $d(\mathrm{~Pb}-\mathrm{Br} 2)=3.002(1) \AA$. Bridging bromide ions (along the $b$ direction) are asymmetrically tilted at $92.7^{\circ}$ with respect to that plane (Figure $\mathrm{S} 2 \mathrm{a}$ ) and have equal $\mathrm{Pb}-\mathrm{Br}$ distances of 2.953(1) Å. Guanidinium ions form hydrogen bonds with halogen atoms of two different layers: $d(\mathrm{H}-\mathrm{Br})=2.7445-2.869 \AA$ (Figure S2b). The cesium ions occupy one type of position with a coordination number of 10 in the smaller voids between the $\mathrm{Pb}-\mathrm{Br}$ octahedra.

Compound III represents a succession of $\mathrm{Cs}\left[\mathrm{C}\left(\mathrm{NH}_{2}\right)_{3}\right]$ $\mathrm{PbBr}_{4}$ with $n=2$ (Figure $2 \mathrm{~b}$ ). The crystal structure of III consists of double $2 \mathrm{D}$ layers of $\mathrm{Pb}-\mathrm{Br}$ octahedra with an average $\mathrm{Pb}-\mathrm{Br}$ distance of $2.977 \AA$, which is slightly longer than that in cubic $\mathrm{CsPbBr}_{3}(d(\mathrm{~Pb}-\mathrm{Br})=2.937 \AA) .{ }^{66}$ Cesium occupies two 
types of positions in the structure: in the cavities within the double layers and in the space between the layers. The corresponding coordination numbers for the two positions are 8 and 10, respectively, with $d(\mathrm{Cs}-\mathrm{Br})=3.775(1)-4.272(1) \AA$. Guanidinium is situated in the void created by the $\mathrm{Pb}-\mathrm{Br}$ octahedra of the two 2D layers and forms hydrogen bonds with the neighboring $\mathrm{Br}$ ions of these two layers with $d(\mathrm{H}-\mathrm{Br})=$ 2.804-2.847 $\AA$, generating a 3D supramolecular network (Figure 2c). Bridging bromide ions (along the $c$ direction) are disordered at a single position (Figure $2 \mathrm{~d}$ ).

Powder XRD patterns of the synthesized compounds were compared to a theoretical pattern (Figure $3 a-c$ ) for testing the overall purity of the substances. For compound I, no impurities were detected in the powder XRD pattern (Figure 3a). Compounds II and III often contain a few percent of each other as an impurity.

Thermogravimetric analysis was performed under inert conditions under an argon atmosphere $(40 \mathrm{~mL} / \mathrm{min}$, ambient pressure), in alumina $\left(\mathrm{Al}_{2} \mathrm{O}_{3}\right)$ crucibles, at a heating rate of $10 \mathrm{~K} / \mathrm{min}$. Compounds I-III exhibit high thermal stabilities (Figure 3d-f). Decomposition starts at approximately $300{ }^{\circ} \mathrm{C}$. Before decomposition, an endothermic process without a mass loss occurs for all three compounds: at $213{ }^{\circ} \mathrm{C}$ for II and III and at $283{ }^{\circ} \mathrm{C}$ for $\mathrm{I}$, which is closer to the decomposition point. These endothermic processes indicate phase transitions, which could be melting or another structural transformation, which in the case of compound $\mathbf{I}$ is followed by the decomposition of the compound.

Absorption Spectra. Having established the crystal structures of compounds I-III, we examined their electronic structure using optical absorption spectroscopy (Figure 4a,b). In particular, we sought to compare the band gap energies with those for the known compositionally and/or structurally related compounds IV-X (Figure $4 a-c$ and Figure S3 in the Supporting Information). These reference compounds were previously reported by other groups: $\mathbf{I V},{ }^{5,11,31} \mathbf{V},{ }^{54} \mathbf{V I},{ }^{66,67}$ VII, ${ }^{1,68,69}$ VIII, $^{70}$ IX, $^{71}$ and $\mathbf{X}^{66}$ In this work, compounds IV-X were grown from acidic solutions (see Methods). The purity of compounds $\mathbf{I}-\mathbf{X}$ was assessed by comparing their powder XRD patterns with the simulated powder patterns generated using single-crystal data (see Figure $3 a-c$ and Figures S4-S10 in the Supporting Information). Single-crystal data for some reference compounds were taken from ICSD cards 92045 (for V), 97851 (for VI), and 27979 (for X) as well as from ref 31 (for IV) and from ref 68 (for VII). Compounds VIII and IX, namely, $\mathrm{CsPb}_{2} \mathrm{Br}_{5}$ and $\left[\mathrm{C}\left(\mathrm{NH}_{2}\right)_{3}\right]_{2} \mathrm{PbBr}_{4}$, had not been structurally characterized prior to this study. Therefore, we determined their crystal structures by single-crystal XRD (for crystallographic details see Figure S3 and Table S2 in the Supporting Information and CCDC entries 1552606 and 1552601) and found good agreement with the powder patterns (Figures S8 and S9 in the Supporting Information). $\mathrm{CsPb}_{2} \mathrm{Br}_{5}$ (VIII, Figure $\mathrm{S} 3 \mathrm{~b}$ ) is a $2 \mathrm{D}$ compound with layers constructed of $\mathrm{Pb}-\mathrm{Br}$ face-sharing distorted square antiprisms and cesium ions located in the interlayer space. This compound is often reported for $\mathrm{Cs}-\mathrm{Pb}-\mathrm{Br}$ systems, along with the $\mathrm{OD}$ perovskite $\mathrm{Cs}_{4} \mathrm{PbBr}_{6}$ and $3 \mathrm{D}$ perovskite $\mathrm{CsPbBr}_{3}{ }^{67,72,73}$ Our single-crystal diffraction data for $\mathrm{CsPb}_{2} \mathrm{Br}_{5}$ are consistent with a powder diffraction pattern reported in ref 70 and in PDF2 (\#00-025-0211). [C( $\left.\left(\mathrm{NH}_{2}\right)_{3}\right]_{2} \mathrm{PbBr}_{4}$ (IX, Figure $\mathrm{S} 3 \mathrm{a})$ crystallizes in the triclinic $P \overline{1}$ space group with a structural motif similar to that of $\left[\mathrm{C}\left(\mathrm{NH}_{2}\right)_{3}\right]_{2} \mathrm{SnCl}_{4}$, as reported by Szafrański et al. ${ }^{74}\left[\mathrm{C}\left(\mathrm{NH}_{2}\right)_{3}\right]_{2} \mathrm{PbBr}_{4}$ consists of $1 \mathrm{D}$ chains of corner-sharing $\left[\mathrm{PbBr}_{5}\right]$ square pyramids, wherein the coordination
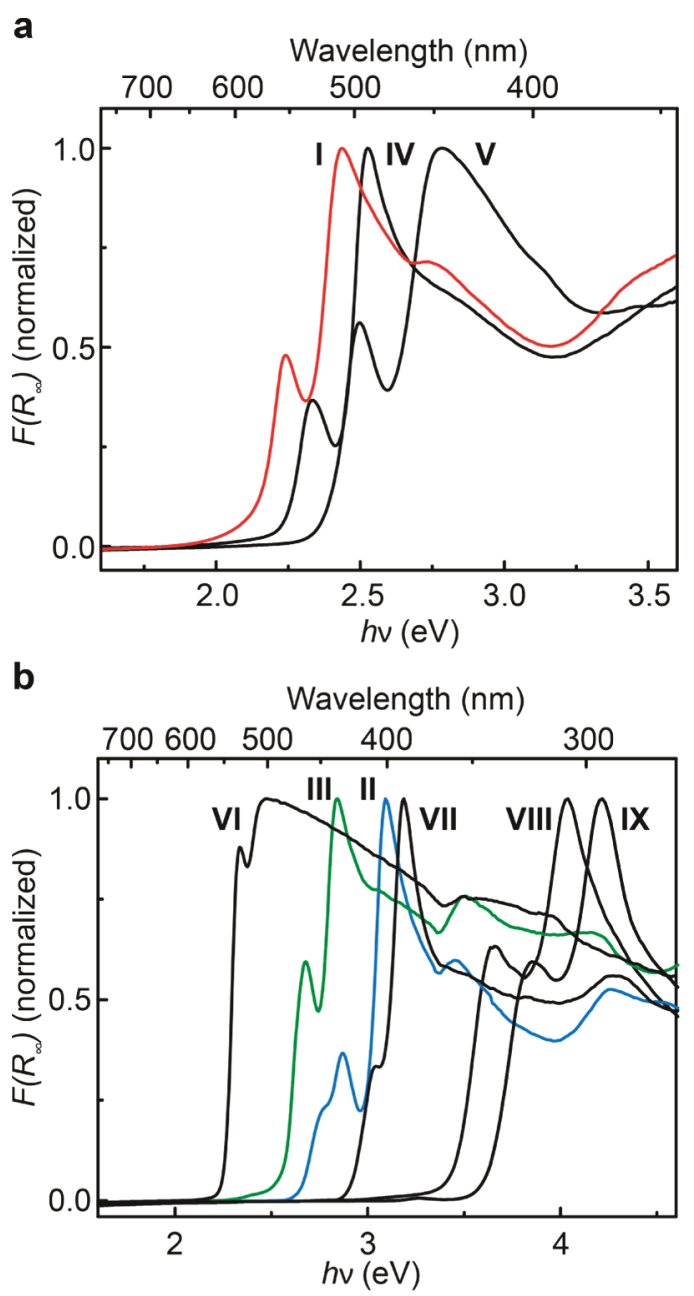

C

\begin{tabular}{|l|l|l|}
\hline \multicolumn{1}{|c|}{ Compounds } & Number & $\mathrm{E}_{\mathrm{g}}(\mathrm{eV})$ \\
\hline $\mathrm{Cs}\left[\mathrm{C}\left(\mathrm{NH}_{2}\right)_{3}\right] \mathrm{PbI}_{4}$ & I & 2.35 \\
\hline $\mathrm{Cs}\left[\mathrm{C}\left(\mathrm{NH}_{2}\right)_{3}\right] \mathrm{PbBr}_{4}$ & II & 2.80 \\
\hline $\mathrm{Cs}\left[\mathrm{C}\left(\mathrm{NH}_{2}\right)_{3}\right] \mathrm{Pb}_{2} \mathrm{Br}_{7}$ & III & 2.76 \\
\hline$\left(\mathrm{n}-\mathrm{C}_{4} \mathrm{H}_{9} \mathrm{NH}_{3}\right)_{2} \mathrm{PbI}_{4}$ & IV & 2.45 \\
\hline$\left[\mathrm{C}\left(\mathrm{NH}_{2}\right)_{3}\right]_{2} \mathrm{PbI}_{4}$ & V & 2.63 \\
\hline $\mathrm{CsPbBr}$ & VI & 2.38 \\
\hline$\left(\mathrm{n}-\mathrm{C}_{4} \mathrm{H}_{9} \mathrm{NH}_{3}\right)_{2} \mathrm{PbBr}_{4}$ & VII & 3.11 \\
\hline $\mathrm{CsPb} \mathrm{Br}_{5}$ & VIII & 3.84 \\
\hline$\left[\mathrm{C}\left(\mathrm{NH}_{2}\right)_{3}\right]_{2} \mathrm{PbBr}_{4}$ & IX & 4.00 \\
\hline $\mathrm{CsPbl}$ & X & \\
\hline
\end{tabular}

Figure 4. (a, b) Kubelka-Munk function $F\left(R_{\infty}\right)=\left(1-R_{\infty}\right)^{2} /$ $R_{\infty}\left(R_{\infty}\right.$ - diffusive reflectance) of I-IX. (c) Table of compounds and their band gaps determined from $\left[F\left(R_{\infty}\right) h v\right]^{2}$ (after subtraction of the excitonic peak from the Kubelka-Munk function), where $F\left(R_{\infty}\right)$ is in Kubelka-Munk units and $h \nu$ is the incident photon energy.

number of $\mathrm{Pb}(\mathrm{II})$ is 6 , including the lone $6 \mathrm{~s}^{2}$ pair of electrons. The guanidinium cations are located between the inorganic chains and form hydrogen-halogen bonds, resulting in a 3D supramolecular structure. This structural analysis underlines the importance of Cs ions for building a stable $2 \mathrm{D}$ perovskite of compound II. Interestingly, the iodide compositional analogue $\left[\mathrm{C}\left(\mathrm{NH}_{2}\right)_{3}\right]_{2} \mathrm{PbI}_{4}(\mathbf{V})$ does form a $2 \mathrm{D}$ lattice, but unlike $\mathbf{I}$, it is 


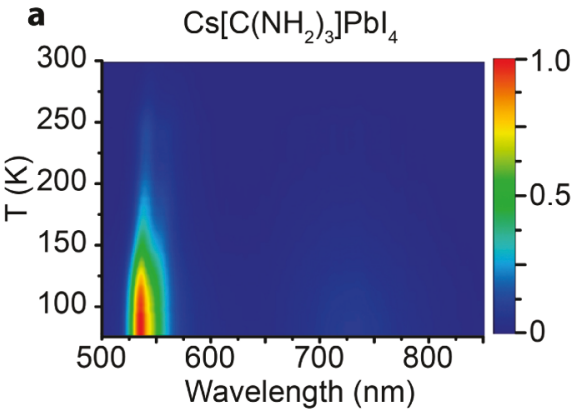

d

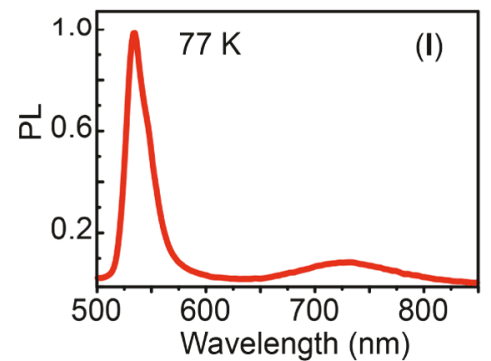

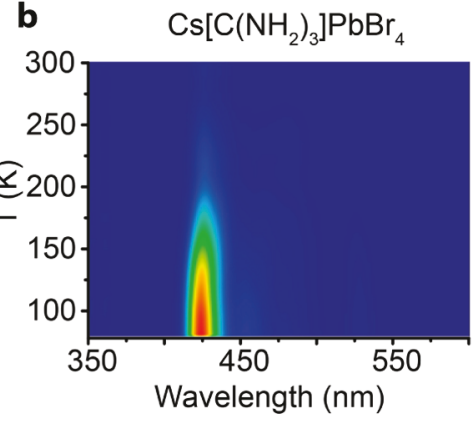

e

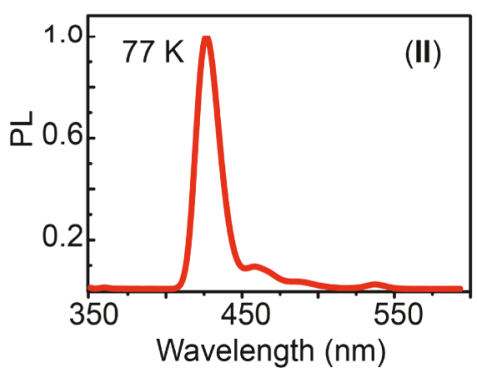

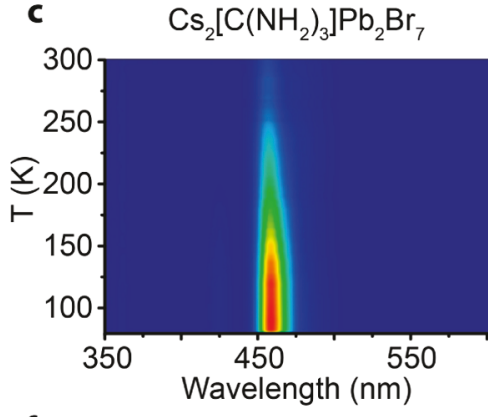

f

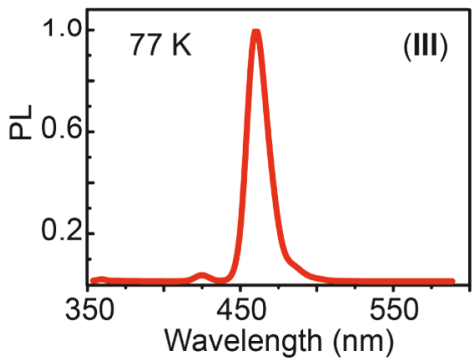

Figure 5. $(\mathrm{a}-\mathrm{c})$ Normalized temperature-dependent PL spectra. The color bar (on the right) represents the intensity for all PL matrices.

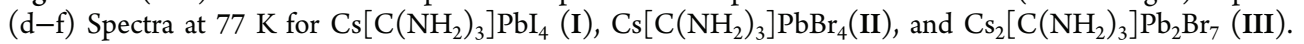

made of corrugated (zigzag) layers (see the structural comparison among I, V, and IV in Figure S11a-c in the Supporting Information). 31,54

Figure $4 \mathrm{a}, \mathrm{b}$ and Figure S12 in the Supporting Information present the normalized Kubelka-Munk (KM) functions, $F\left(R_{\infty}\right)$, for all 10 compounds. This function is derived from the diffuse reflectance spectra of the powdered samples. This function is estimated as $F\left(R_{\infty}\right)=\alpha / S=\left(1-R_{\infty}\right)^{2} / R_{\infty}$, where $\alpha$ is the absorption coefficient, $S$ is the scattering coefficient, and $R_{\infty}$ is the reflectance of an infinitely thick layer. Band gap energies were estimated by plotting $\left[F\left(R_{\infty}\right) \cdot h \nu\right]^{2}$ (where $F\left(R_{\infty}\right)$ is in Kubelka-Munk units and $h \nu$ is the incident photon energy) versus energy $(h \nu)$. The excitonic peaks were subtracted from the Kubelka-Munk function for the band gap determination (Figure S13 in the Supporting Information). ${ }^{57}$ Conventional optical absorption spectra for all compounds I-X are presented in Figure S14 in the Supporting Information.

The most important comparison is between $\left(\mathrm{n}-\mathrm{C}_{4} \mathrm{H}_{9} \mathrm{NH}_{3}\right)_{2} \mathrm{PbX}_{4}$ (IV and VII) and $\mathrm{Cs}\left[\mathrm{C}\left(\mathrm{NH}_{2}\right)_{3}\right] \mathrm{PbX}_{4}$ (I and II) because these compounds consist of flat sheets of $\mathrm{PbX}_{6}$ (unlike the corrugated sheets in V). The band gaps for the Cs guanidinium based compounds are smaller by $0.1-0.35 \mathrm{eV}$. This observation correlates well with the smaller interlayer ions reducing the average thickness of one layer (center to center distance) and, hence, also reducing the electronic isolation of the $\mathrm{PbX}_{6}$ layers. For the case of iodides, the average thickness of one layer is $9.78 \AA$ in I ( $13.8 \AA$ in IV); correspondingly, the specific density of $I$ is $1.54 \mathrm{~g} \mathrm{~cm}^{-3}$ greater than that of IV $\left(4.162 \mathrm{~g} \mathrm{~cm}^{-3}\right.$ vs $\left.2.702 \mathrm{~g} \mathrm{~cm}^{-3}\right)$, whereas their molecular weights are similar (907.79 and $863.109 \mathrm{~g} \mathrm{~mol}^{-1}$, respectively), pointing to much smaller molar volumes obtained with smaller interlayer cations. Interestingly, despite its similar density, compound $\mathbf{V}$ shows a wider band gap of $2.63 \mathrm{eV}$ (Figure 4c), arguably due to the corrugated 2D structure (Figure S11c in the Supporting Information). Another important factor is a distortion of the $\mathrm{Pb}-\mathrm{X}$ octahedra. It can be described by a deviation of $\mathrm{Pb}-\mathrm{X}-\mathrm{Pb}$ angles from $180^{\circ}$. Moreover, in-plane (in the plane of propagation of inorganic layers) distortions were shown to have a more significant influence on the band gap than the out-of-plane deviations. ${ }^{75,76}$ When $\left(\mathrm{n}-\mathrm{C}_{4} \mathrm{H}_{9} \mathrm{NH}_{3}\right)_{2} \mathrm{PbI}_{4}$ and $\mathrm{Cs}\left[\mathrm{C}\left(\mathrm{NH}_{2}\right)_{3}\right] \mathrm{PbI}_{4}$ are compared (Figure S15 in the Supporting Information), the difference in the band gaps is consistent with a degree of distortion of $\mathrm{Pb}-\mathrm{I}$ octahedra. The in-plane deviation of the $\mathrm{Pb}-\mathrm{I}-\mathrm{Pb}$ angle from $180^{\circ}$ for $\left(\mathrm{n}-\mathrm{C}_{4} \mathrm{H}_{9} \mathrm{NH}_{3}\right)_{2} \mathrm{PbI}_{4}$ is as significant as $24.36^{\circ}$, while for $\mathrm{Cs}\left[\mathrm{C}\left(\mathrm{NH}_{2}\right)_{3}\right] \mathrm{PbI}_{4}$ the maximum angle of deviation is $18.43^{\circ}$.

The Kubelka-Munk absorption functions of $2 \mathrm{D}$ perovskites of variable slab thickness II and III point to a smaller band gap, as expected, for thicker $\mathrm{Pb}-\mathrm{Br}$ slabs of III. In addition, the effect of the interlayer spacing is clearly seen in the approximately $0.35 \mathrm{eV}$ wider gap of VII (flat $1 \mathrm{D}$ sheets) in comparison to that of II. Both II and III exhibit intermediate band gap values in comparison to those of compounds with higher and lower dimensionalities: i.e., $\mathrm{CsPbBr}_{3}$ (VI, 3D) and $\left[\mathrm{C}\left(\mathrm{NH}_{2}\right)_{3}\right]_{2} \mathrm{PbBr}_{4}(\mathrm{IX}, 1 \mathrm{D})$, respectively.

Photoluminescence. Optical emission spectra (Figure 5) were recorded in the range of $77-300 \mathrm{~K}$ for I-III. Only compound III exhibits a measurable PL intensity at room temperature (Figure 5c). All three compounds are brightly emissive to the naked eye under UV light at $77 \mathrm{~K}$. For this temperature, Figure $5 \mathrm{~d}-\mathrm{f}$ present the luminescence spectra, while the entire temperature dependence is plotted as color maps in Figure 5a-c. The presence of minor emission peaks in Figure $5 b, c$ suggests that compounds II and III contain small impurities of each other, as also concluded from the powder XRD patterns. For the PL spectrum of $\mathbf{I}$, in addition to the main emission peak at $535 \mathrm{~nm}$, a broader, low-intensity feature at $650-800 \mathrm{~nm}$ was detected.

In order to understand the origin of this feature, we performed time-resolved photoluminescence measurement at various temperatures (Figure S16 in the Supporting Information). It can be seen that while the emission at $535 \mathrm{~nm}$ decays very quickly, within $10 \mathrm{~ns}$, the long-wavelength band relaxes much more slowly (sub $\mu$ s range) and the relaxation becomes even slower upon cooling to $200 \mathrm{~K}$. These features of the spectrally broad and long-lived emission is consistent with the 
phenomenon of self-trapped excitons that was recently observed in 2D layered perovskites. ${ }^{35,76,77}$ Often, the emission of self-trapped excitons accompanies narrow-band shorterwavelength excitonic emission, such as in the present case. ${ }^{35,76}$ Thus, we believe that we observed an excitonic emission at 535 $\mathrm{nm}$ and self-trapped excitons at $650-800 \mathrm{~nm}$.

Photoconductivity. Semiconductive properties of the obtained compounds are manifested in the production of free charge carriers under light excitation and in the photoconductivity effects. The dark specific resistivity values are approximately $3 \times 10^{8}$ and $5 \times 10^{9} \Omega \mathrm{cm}$ for compounds I and III, respectively. The photoconductivity spectra (Figure 6) of two

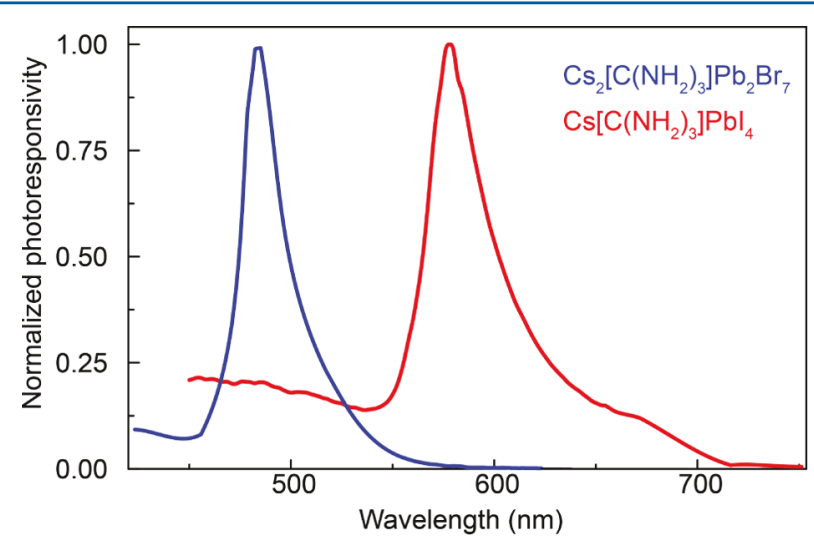

Figure 6. Room-temperature photoconductivity of $\mathrm{Cs}\left[\mathrm{C}\left(\mathrm{NH}_{2}\right)_{3}\right] \mathrm{PbI}_{4}$ (I) and $\mathrm{Cs}_{2}\left[\mathrm{C}\left(\mathrm{NH}_{2}\right)_{3}\right] \mathrm{Pb}_{2} \mathrm{Br}_{7}$ (III) single crystals.

single crystals of compounds I and III exhibit similar features. First, a shoulder on the shorter wavelength side corresponds to band gap absorption. Second, sharp peaks appear at approximately $1 \mathrm{~mA} \mathrm{~W}^{-1}$ for $\mathrm{Cs}\left[\mathrm{C}\left(\mathrm{NH}_{2}\right)_{3}\right] \mathrm{PbI}_{4}(\mathrm{I})$ and $9 \mathrm{~mA} \mathrm{~W}^{-1}$ for $\mathrm{Cs}_{2}\left[\mathrm{C}\left(\mathrm{NH}_{2}\right)_{3}\right] \mathrm{Pb}_{2} \mathrm{Br}_{7}$ (III). Such photopeaks have been recently reported for $\mathrm{APbX}_{3}$ perovskite single crystals ${ }^{72,78,79}$ and can be explained by the thickness (depth)-dependent absorption and charge transport phenomena. Two competing effects determine the photocurrent in this case. First, the charges produced in the crystal volume are more effectively collected on the electrodes, while the charges produced on or close to the surface demonstrate decreased charge transport characteristics, likely due to the trapping of surface charges. When this trapping effect is combined with the absorption spectrum, a peak is expected at the onset of the absorption, not at the absorption peak. The wavelength of the peak, which is essentially equal to the band gap energy, is the wavelength at which sufficiently intense light propagates into the bulk region. At higher energies (shorter wavelengths), the higher absorption coefficient will limit the absorption to the near-surface regions. A third feature that differentiates compounds I and III form $\mathrm{APbX}_{3}$ perovskite single crystals ${ }^{72,78,79}$ is the long-wavelength photocurrent tail at energies well below the band gap; this tail is most pronounced for compound I. This region may be attributed to the photocurrent involving the midgap trap states. Interestingly, the charges produced in the SC volume (sharp peak and shoulder at longer wavelengths) are delayed in comparison to charges from the surface, corresponding to a decrease in the phase of the photoresponse (Figure S17 in the Supporting Information). This may be due to the moderate charge mobility in these compounds.

Electronic Structure. Compounds I-III have qualitatively similar electronic structures. We chose $\mathrm{Cs}\left[\mathrm{C}\left(\mathrm{NH}_{2}\right)_{3}\right] \mathrm{PbBr}_{4}$ (II) as an example for the following detailed discussion. The quantitative differences such as the band gaps and their relation to composition are addressed below. The density of states (DoS) per primitive cell is plotted in Figure 7. The solid black line

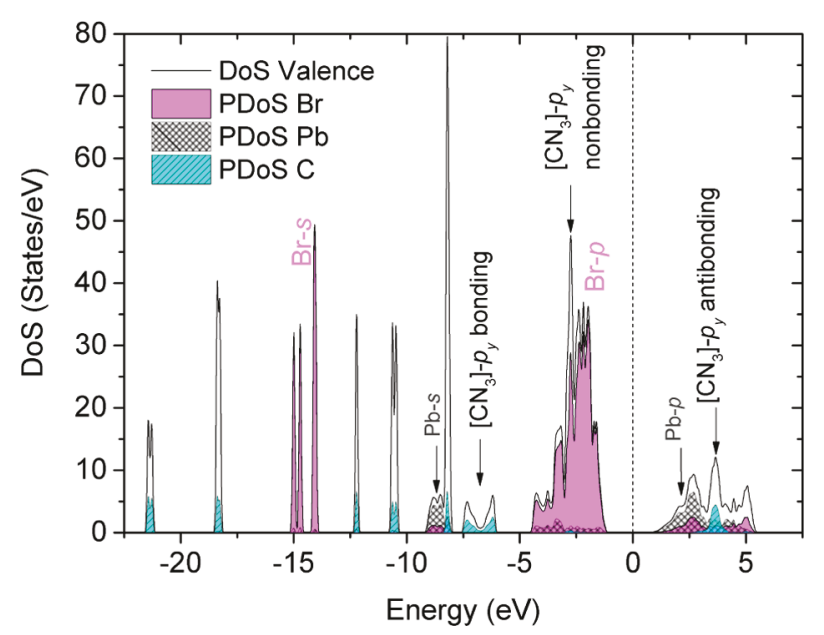

Figure 7. Electronic density of states (DoS) per primitive cell per eV in $\mathrm{Cs}\left[\mathrm{C}\left(\mathrm{NH}_{2}\right)_{3}\right] \mathrm{PbBr}_{4}$ (II).

represents the sum of all valence states, and the contributions of selected species, i.e., the partial density of states (PDoS), are represented by colored areas.

The interaction of bromine with the other atoms is rather ionic, as can be inferred from the nearly $100 \%$ coverage (magenta areas) of the DoS in the regions where bromine contributes. The main contribution of lead to the occupied states originates from the electrons in the 6 s orbitals at approximately $8 \mathrm{eV}$ below the Fermi level, represented by the dashed gray area. The remaining valence electrons belong to guanidinium cations. The bonding, nonbonding, and antibonding combinations of the $\mathrm{CN}_{3} \pi$ system are labeled in Figure 7 . These states are not stabilized by the interaction with the protons and appear higher in energy. The nonbonding section has a negligible contribution from carbon (cyan area) as expected for the nearly ideal $D_{3 h}$ symmetry of guanidinium within this structure. The $\pi$ contribution to the $\mathrm{C}-\mathrm{N}$ bonds is also visible in the electron localization function (ELF, shown in Figure 8), ${ }^{61}$ where the bc cut (left side) and the ac cut (right side) show different widths of the bonding attractor: i.e., the $\mathrm{C}-\mathrm{N}$ bond cross section has an oval shape. The ELF also confirms the dominant ionic interaction between all $\mathrm{Pb}-\mathrm{Br}$ and $\mathrm{Cs}-\mathrm{Br}$ pairs, with the formation of nearly spherical closed shells. In the present case, the guanidinium-Br hydrogen bond is a proton bridge type of bond. Due to the deficit of one electron in the cation, the electron cloud is pulled by nitrogen and carbon toward the center, leaving the positive protons as an outer layer to interact with the bromine atoms. Accordingly, the very small contribution of hydrogen to the DoS (not highlighted in Figure 7) shows negligible mixing with bromine states. Note that the closed-shell-like ELF attractor of $\mathrm{Br}$ is distorted in a way that "avoids" the protons, which is typical for ionic interactions.

All three compounds feature guanidinium cation stacking in alternating orientations along a crystallographic axis, which suggests a stabilizing interaction between neighboring cations. We find that this stacking allows van der Waals interactions involving the easily polarizable $\pi$ electron cloud of guanidinium cations. This conclusion is corroborated by the small contribution 


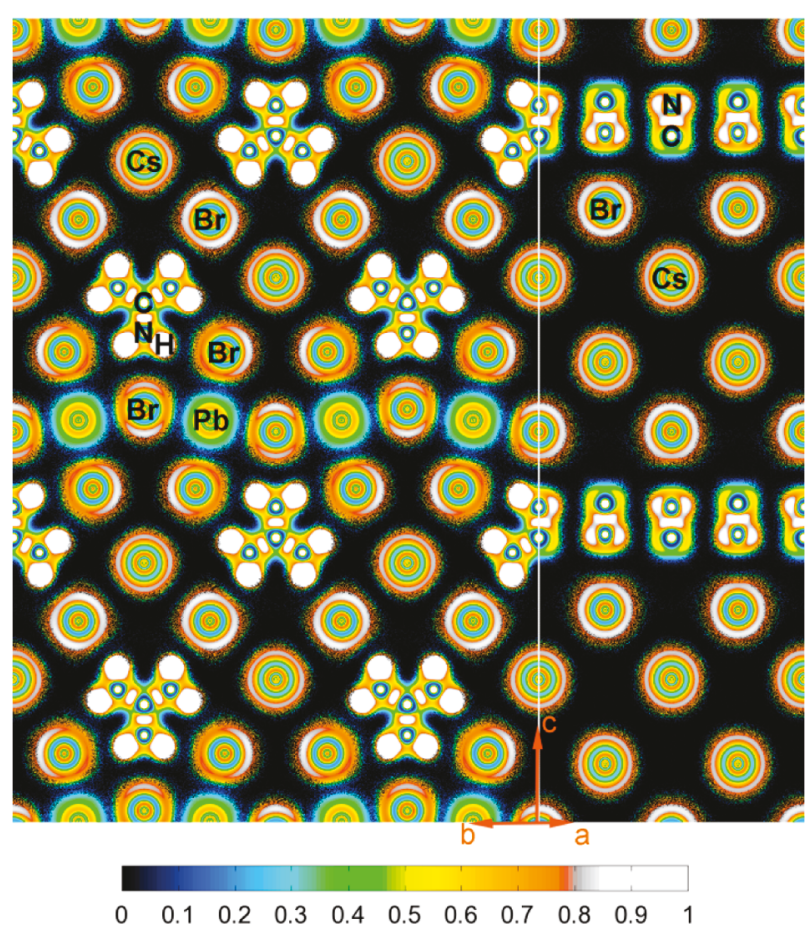

Figure 8. ELF planar cut at $x=0$ (left) and $y=0$ (right), each covering $2 \times 2$ unit cells of $\mathrm{Cs}\left[\mathrm{C}\left(\mathrm{NH}_{2}\right)_{3}\right] \mathrm{PbBr}_{4}$. Crystallographic sites are labeled with the name of the corresponding elements.

of the carbon states to the nonbonding peak just below $-2.5 \mathrm{eV}$ (see Figure 7). The latter can appear only if the $D_{3 h}$ symmetry is broken and the $\pi$ electron cloud is polarized. At the same time, the $\pi$-bonding band appearing at $-6.8 \mathrm{eV}$ (see Figure 9) disperses along the $\mathrm{W}-\mathrm{R}$ segment in reciprocal space. This band dispersion of approximately $0.7 \mathrm{eV}$ is significant, especially

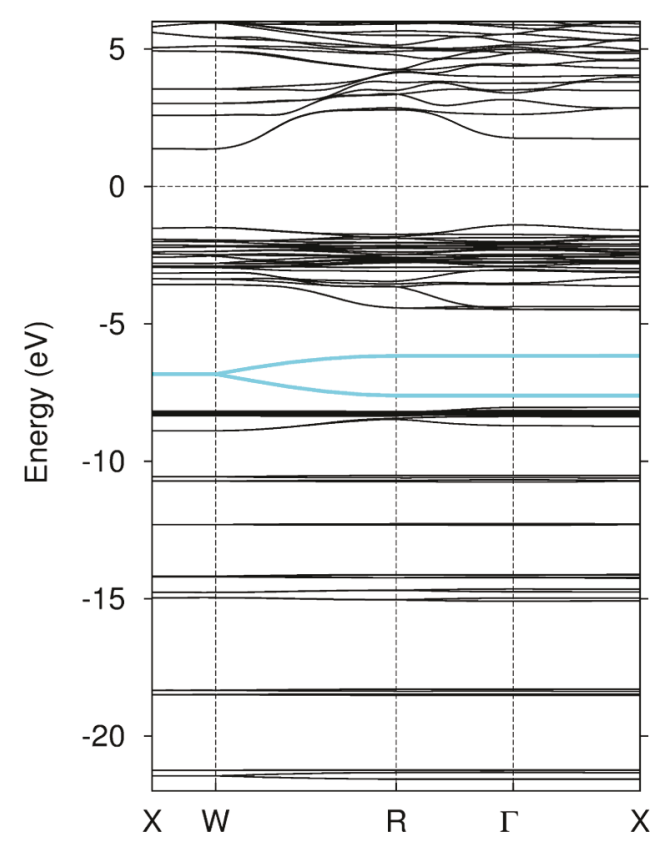

Figure 9. Electronic band structure of $\mathrm{Cs}\left[\mathrm{C}\left(\mathrm{NH}_{2}\right)_{3}\right] \mathrm{PbBr}_{4}$ (II) from DFT calculations. The flatness of the majority of the occupied bands indicates the localized character of the states. Note the exceptional dispersion along the $\mathrm{W}-\mathrm{R}$ segment of the $\pi$-bonding guanidinium states (in cyan at approximately $-6.8 \mathrm{eV}$ ). in comparison to the generally flat band structure of such systems. The alternate stacking allows the small energy cost for polarizing the shells to be overcompensated by the interaction between the induced dipoles, resulting in higher stability.

Compounds I-III are all semiconductors. DFT predicts that the highest occupied and lowest empty bands predominantly consist of halide $\mathrm{p}$ orbital and $\mathrm{Pb} \mathrm{p}$ orbital contributions, respectively. The calculated band gaps are approximately $2.7 \mathrm{eV}$ for $\mathrm{Cs}\left[\mathrm{C}\left(\mathrm{NH}_{2}\right)_{3}\right] \mathrm{PbBr}_{4}, 2.2 \mathrm{eV}$ for $\mathrm{Cs}_{2}\left[\mathrm{C}\left(\mathrm{NH}_{2}\right)_{3}\right] \mathrm{Pb}_{2} \mathrm{Br}_{7}$, and $2.0 \mathrm{eV}$ for $\mathrm{Cs}\left[\mathrm{C}\left(\mathrm{NH}_{2}\right)_{3}\right] \mathrm{PbI}_{4}$. This trend is consistent with the measured absorption spectra (Figure 4) and can be understood in terms of basic quantum-mechanical principles. The band gap increases with the confinement, i.e., with the decreasing lead halide slab thickness (from $n=2$ to $n=1$ ) or on moving from heavier iodide to lighter bromide. Bromine is more electronegative than iodine, and therefore, the center of the valence and conduction bands should be closer in energy for the iodides (compound I), resulting in a smaller gap in this case.

\section{CONCLUSIONS}

In conclusion, we presented the synthesis and characterization of three layered lead halide perovskite compounds, containing a mixture of two stable interlayer cations in their structure (cesium and guanidinium ): $\mathrm{Cs}\left[\mathrm{C}\left(\mathrm{NH}_{2}\right)_{3}\right] \mathrm{PbI}_{4}(\mathrm{I}), \mathrm{Cs}\left[\mathrm{C}\left(\mathrm{NH}_{2}\right)_{3}\right] \mathrm{PbBr}_{4}$ (II), and $\mathrm{Cs}_{2}\left[\mathrm{C}\left(\mathrm{NH}_{2}\right)_{3}\right] \mathrm{Pb}_{2} \mathrm{Br}_{7}$ (III). The two interlayer cations act synergistically to enable stable $2 \mathrm{D}$ perovskites through the van der Waals interactions between guanidinium cations and through hydrogen-halogen bonds between guanidinium cations and halide ions of different layers. $\mathrm{Cs}^{+}$ions fill the small voids within the $\mathrm{Pb}-\mathrm{Br}$ layer in III, in addition to also occupying the interlayer space. All three compounds were shown to possess high thermal stability, up to above $300{ }^{\circ} \mathrm{C}$. The compounds exhibit clear signatures of strong quantum confinement. Narrow-band photoconductive response was observed, indicating a balance between the optical absorption effects and the varying charge transport efficiency in the bulk and at the surface of the material.

These findings have strong relevance to perovskite thin-film photovoltaic research. In particular, recent studies have increasingly departed from the archetypical $\mathrm{APbX}_{3}$-like compound $\mathrm{CH}_{3} \mathrm{NH}_{3} \mathrm{PbI}_{3}$ to multicationic and multi-ionic formulations such as that in ref 80 , wherein four A-site cations were used $\left(\mathrm{CH}_{3} \mathrm{NH}_{3}{ }^{+}, \mathrm{CH}\left(\mathrm{NH}_{2}\right)_{2}{ }^{+}, \mathrm{Cs}^{+}, \mathrm{Rb}^{+}\right)$. Moreover, adding guanidinium ions has been reported to improve solar cell characteristics. $^{81,82}$ Clearly, structural studies within this compositional space, as shown here for mixed-cation Cs-guanidinium systems, might unravel the complexities of such optoelectronic systems.

\section{ASSOCIATED CONTENT}

\section{Supporting Information}

The Supporting Information is available free of charge on the ACS Publications website at DOI: 10.1021/acs.inorgchem.7b01204.

Photographs of compounds I and III under daylight and UV illumination (at $77 \mathrm{~K}$ ), crystallographic data for I-III, VIII, and IX, absorption spectra for I-X, powder XRD for IV-X, comparison of crystal structures for I, IV, and $\mathrm{V}$, excitonic peak subtraction from the KubelkaMunk function of I, time-resolved PL spectra at various temperatures for I, and photoresponce for single crystals of I and III (PDF) 


\section{Accession Codes}

CCDC 1552601-1552606 contain the supplementary crystallographic data for this paper. These data can be obtained free of charge via www.ccdc.cam.ac.uk/data_request/cif, or by emailing data_request@ccdc.cam.ac.uk, or by contacting The Cambridge Crystallographic Data Centre, 12 Union Road, Cambridge CB2 1EZ, UK; fax: +44 1223336033.

\section{AUTHOR INFORMATION}

\section{Corresponding Author}

*M.V.K.: e-mail, mvkovalenko@ethz.ch; tel, +41 0446334156. ORCID 1

Sergii Yakunin: 0000-0002-6409-0565

Maksym V. Kovalenko: 0000-0002-6396-8938

\section{Author Contributions}

${ }^{\S}$ O.N. and M.R.K. contributed equally to this work:

\section{Notes}

The authors declare no competing financial interest.

\section{ACKNOWLEDGMENTS}

This work was financially supported by the European Union through the FP7 (ERC Starting Grant NANOSOLID, GA No. 306733) and in part by the Swiss Federal Commission for Technology and Innovation (CTI-No. 18614.1 PFNM-NM). The authors thank Christian Mensing for thermal analysis of the synthesized compounds (DTA/TG) and Prof. Masanori Koshimizu for providing crystallographic information file of $\left(\mathrm{n}-\mathrm{C}_{4} \mathrm{H}_{9} \mathrm{NH}_{3}\right)_{2} \mathrm{PbBr}_{4}$.

\section{REFERENCES}

(1) Mitzi, D. B.; Chondroudis, K.; Kagan, C. R. Organic-inorganic electronics. IBM J. Res. Dev. 2001, 45, 29-45.

(2) Chondroudis, K.; Mitzi, D. B. Electroluminescence from an organic-inorganic perovskite incorporating a quaterthiophene dye within lead halide perovskite layers. Chem. Mater. 1999, 11, 30283030.

(3) Umebayashi, T.; Asai, K.; Kondo, T.; Nakao, A. Electronic structures of lead iodide based low-dimensional crystals. Phys. Rev. B: Condens. Matter Mater. Phys. 2003, 67, 155405.

(4) Ishihara, T.; Takahashi, J.; Goto, T. Exciton state in twodimensional perovskite semiconductor $\left(\mathrm{C}_{10} \mathrm{H}_{21} \mathrm{NH}_{3}\right)_{2} \mathrm{PbI}_{4}$. Solid State Commun. 1989, 69, 933-936.

(5) Stoumpos, C. C.; Cao, D. H.; Clark, D. J.; Young, J.; Rondinelli, J. M.; Jang, J. I.; Hupp, J. T.; Kanatzidis, M. G. Ruddlesden-Popper hybrid lead iodide perovskite $2 \mathrm{D}$ homologous semiconductors. Chem. Mater. 2016, 28, 2852-2867.

(6) Dohner, E. R.; Jaffe, A.; Bradshaw, L. R.; Karunadasa, H. I. Intrinsic white-light emission from layered hybrid perovskites. J. Am. Chem. Soc. 2014, 136, 13154-13157.

(7) Saparov, B.; Mitzi, D. B. Organic-inorganic perovskites: structural versatility for functional materials design. Chem. Rev. 2016, 116, 4558-4596.

(8) Stoumpos, C. C.; Kanatzidis, M. G. Halide perovskites: poor man's high-performance semiconductors. Adv. Mater. 2016, 28, 57785793.

(9) Aleksandrov, K. S.; Bartolom, J. Structural distortions in families of perovskite-like crystals. Phase Transitions 2001, 74, 255-335.

(10) Lemmerer, A.; Billing, D. G. Synthesis, characterization and phase transitions of the inorganic-organic layered perovskite-type hybrids $\left[\left(\mathrm{C}_{\mathrm{n}} \mathrm{H}_{2 \mathrm{n}+1} \mathrm{NH}_{3}\right)_{2} \mathrm{PbI}_{4}\right], \mathrm{n}=7,8,9$ and 10. Dalton Trans. 2012, 41, 1146-1157.

(11) Billing, D. G.; Lemmerer, A. Synthesis, characterization and phase transitions in the inorganic-organic layered perovskite-type hybrids $\left[\left(\mathrm{C}_{\mathrm{n}} \mathrm{H}_{2 \mathrm{n}+1} \mathrm{NH}_{3}\right)_{2} \mathrm{PbI}_{4}\right], \mathrm{n}=4,5$ and 6. Acta Crystallogr., Sect. $B$ : Struct. Sci. 2007, 63, 735-747.
(12) Billing, D. G.; Lemmerer, A. Synthesis, characterization and phase transitions of the inorganic-organic layered perovskite-type hybrids $\left[\left(\mathrm{C}_{\mathrm{n}} \mathrm{H}_{2 \mathrm{n}+1} \mathrm{NH}_{3}\right)_{2} \mathrm{PbI}_{4}\right](\mathrm{n}=12,14,16$ and 18). New J. Chem. 2008, 32, 1736-1746.

(13) Mao, L.; Wu, Y.; Stoumpos, C. C.; Wasielewski, M. R.; Kanatzidis, M. G. White-light emission and structural distortion in new corrugated two-dimensional lead bromide perovskites. J. Am. Chem. Soc. 2017, 139, 5210-5215.

(14) Stoumpos, C. C.; Frazer, L.; Clark, D. J.; Kim, Y. S.; Rhim, S. H.; Freeman, A. J.; Ketterson, J. B.; Jang, J. I.; Kanatzidis, M. G. Hybrid germanium iodide perovskite semiconductors: active lone pairs, structural distortions, direct and indirect energy gaps, and strong nonlinear optical properties. J. Am. Chem. Soc. 2015, 137, 6804-6819.

(15) Stoumpos, C. C.; Kanatzidis, M. G. The renaissance of halide perovskites and their evolution as emerging semiconductors. Acc. Chem. Res. 2015, 48, 2791-2802.

(16) Mao, L.; Tsai, H.; Nie, W.; Ma, L.; Im, J.; Stoumpos, C. C.; Malliakas, C. D.; Hao, F.; Wasielewski, M. R; Mohite, A. D.; Kanatzidis, M. G. Role of organic counterion in lead- and tin-based two-dimensional semiconducting iodide perovskites and application in planar solar cells. Chem. Mater. 2016, 28, 7781-7792.

(17) Stoumpos, C. C.; Mao, L.; Malliakas, C. D.; Kanatzidis, M. G. Structure-band gap relationships in hexagonal polytypes and lowdimensional structures of hybrid tin iodide perovskites. Inorg. Chem. 2017, 56, 56-73.

(18) Smith, I. C.; Smith, M. D.; Jaffe, A.; Lin, Y.; Karunadasa, H. I. Between the sheets: postsynthetic transformations in hybrid perovskites. Chem. Mater. 2017, 29, 1868-1884.

(19) Blancon, J.-C.; Tsai, H.; Nie, W.; Stoumpos, C. C.; Pedesseau, L.; Katan, C.; Kepenekian, M.; Soe, C. M. M.; Appavoo, K.; Sfeir, M. Y.; Tretiak, S.; Ajayan, P. M.; Kanatzidis, M. G.; Even, J.; Crochet, J. J.; Mohite, A. D. Extremely efficient internal exciton dissociation through edge states in layered 2D perovskites. Science 2017, 355, 1288.

(20) Lermer, C.; Harm, S. P.; Birkhold, S. T.; Jaser, J. A.; Kutz, C. M.; Mayer, P.; Schmidt-Mende, L.; Lotsch, B. V. Benzimidazolium lead halide perovskites: effects of anion substitution and dimensionality on the bandgap. Z. Anorg. Allg. Chem. 2016, 642, 1369-1376.

(21) Lermer, C.; Birkhold, S. T.; Moudrakovski, I. L.; Mayer, P.; Schoop, L. M.; Schmidt-Mende, L.; Lotsch, B. V. Toward fluorinated spacers for MAPI-derived hybrid perovskites: synthesis, characterization, and phase transitions of $\left(\mathrm{FC}_{2} \mathrm{H}_{4} \mathrm{NH}_{3}\right)_{2} \mathrm{PbCl}_{4}$. Chem. Mater. 2016, 28, 6560-6566.

(22) Stoumpos, C. C.; Malliakas, C. D.; Peters, J. A.; Liu, Z.; Sebastian, M.; Im, J.; Chasapis, T. C.; Wibowo, A. C.; Chung, D. Y.; Freeman, A. J.; Wessels, B. W.; Kanatzidis, M. G. Crystal growth of the perovskite semiconductor $\mathrm{CsPbBr}$ : a new material for high-energy radiation detection. Cryst. Growth Des. 2013, 13, 2722-2727.

(23) Manser, J. S.; Saidaminov, M. I.; Christians, J. A.; Bakr, O. M.; Kamat, P. V. Making and breaking of lead halide perovskites. Acc. Chem. Res. 2016, 49, 330-338.

(24) Saidaminov, M. I.; Abdelhady, A. L.; Murali, B.; Alarousu, E.; Burlakov, V. M.; Peng, W.; Dursun, I.; Wang, L.; He, Y.; Maculan, G. High-quality bulk hybrid perovskite single crystals within minutes by inverse temperature crystallization. Nat. Commun. 2015, 6, 7586.

(25) Saidaminov, M. I.; Abdelhady, A. L.; Maculan, G.; Bakr, O. M. Retrograde solubility of formamidinium and methylammonium lead halide perovskites enabling rapid single crystal growth. Chem. Commun. 2015, 51, 17658-17661.

(26) Zhumekenov, A. A.; Saidaminov, M. I.; Haque, M. A.; Alarousu, E.; Sarmah, S. P.; Murali, B.; Dursun, I.; Miao, X.-H.; Abdelhady, A. L.; $\mathrm{Wu}, \mathrm{T}$. Formamidinium lead halide perovskite crystals with unprecedented long carrier dynamics and diffusion length. ACS Energy Lett. 2016, 1, 32-37.

(27) Berry, J.; Buonassisi, T.; Egger, D. A.; Hodes, G.; Kronik, L.; Loo, Y. L.; Lubomirsky, I.; Marder, S. R.; Mastai, Y.; Miller, J. S. Hybrid organic-inorganic perovskites (HOIPs): opportunities and challenges. Adv. Mater. 2015, 27, 5102-5112. 
(28) Brenner, T. M.; Egger, D. A.; Kronik, L.; Hodes, G.; Cahen, D. Hybrid organic-inorganic perovskites: low-cost semiconductors with intriguing charge-transport properties. Nat. Rev. Mater. 2016, 1, 15007.

(29) Kulbak, M.; Cahen, D.; Hodes, G. How important is the organic part of lead halide perovskite photovoltaic cells? Efficient $\mathrm{CsPbBr}_{3}$ cells. J. Phys. Chem. Lett. 2015, 6, 2452-2456.

(30) Wang, S.; Mitzi, D. B.; Feild, C. A.; Guloy, A. Synthesis and characterization of $\left[\mathrm{NH}_{2} \mathrm{C}(\mathrm{I}): \mathrm{NH}_{2}\right]_{3} \mathrm{MI}_{5}(\mathrm{M}=\mathrm{Sn}, \mathrm{Pb})$ : stereochemical activity in divalent tin and lead halides containing single < 110> perovskite sheets. J. Am. Chem. Soc. 1995, 117, 5297-5302.

(31) Mitzi, D. B. Synthesis, crystal structure, and optical and thermal properties of $\left(\mathrm{C}_{4} \mathrm{H}_{9} \mathrm{NH}_{3}\right)_{2} \mathrm{MI}_{4}(\mathrm{M}=\mathrm{Ge}, \mathrm{Sn}, \mathrm{Pb})$. Chem. Mater. 1996, $8,791-800$

(32) Steadman, J. P.; Willett, R. D. The crystal structure of $\left(\mathrm{C}_{2} \mathrm{H}_{5} \mathrm{NH}_{3}\right)_{2} \mathrm{CuCl}_{4}$. Inorg. Chim. Acta 1970, 4, 367-371.

(33) Bellitto, C.; Day, P. Feature article. Organic-intercalated halogenochromates (II): low-dimensional magnets. J. Mater. Chem. 1992, 2, 265-271.

(34) Dolzhenko, Y. I.; Inabe, T.; Maruyama, Y. In situ X-ray observation on the intercalation of weak interaction molecules into perovskite-type layered crystals $\left(\mathrm{C}_{9} \mathrm{H}_{19} \mathrm{NH}_{3}\right)_{2} \mathrm{PbI}_{4}$ and $\left(\mathrm{C}_{10} \mathrm{H}_{21} \mathrm{NH}_{3}\right)_{2} \mathrm{CdCl}_{4}$. Bull. Chem. Soc. Jpn. 1986, 59, 563-567.

(35) Smith, M. D.; Pedesseau, L.; Kepenekian, M.; Smith, I. C.; Katan, C.; Even, J.; Karunadasa, H. I. Decreasing the electronic confinement in layered perovskites through intercalation. Chem. Sci. 2017, 8, 1960-1968.

(36) Ishihara, T.; Hirasawa, M.; Goto, T. Optical properties and electronic structures of self-organized quantum well $\left(\mathrm{C}_{\mathrm{n}} \mathrm{H}_{2 \mathrm{n}+1} \mathrm{NH}_{3}\right)_{2} \mathrm{PbX}_{4}(\mathrm{X}=\mathrm{I}, \mathrm{Br}, \mathrm{Cl})$. Jpn. J. Appl. Phys. 1995, 34, $71-73$.

(37) Calabrese, J.; Jones, N. L.; Harlow, R. L.; Herron, N.; Thorn, D. L.; Wang, Y. Preparation and characterization of layered lead halide compounds. J. Am. Chem. Soc. 1991, 113, 2328-2330.

(38) Lemmerer, A.; Billing, D. G. Lead halide inorganic-organic hybrids incorporating diammonium cations. CrystEngComm 2012, 14, $1954-1966$.

(39) Slavney, A. H.; Smaha, R. W.; Smith, I. C.; Jaffe, A.; Umeyama, D.; Karunadasa, H. I. Chemical approaches to addressing the instability and toxicity of lead-halide perovskite absorbers. Inorg. Chem. 2017, $56,46-55$

(40) Mitzi, D. B.; Feild, C. A.; Harrison, W. T. A.; Guloy, A. M. Conducting tin halides with a layered organic-based perovskite structure. Nature 1994, 369, 467-469.

(41) Stoumpos, C. C.; Soe, C. M. M.; Tsai, H.; Nie, W.; Blancon, J.C.; Cao, D. H.; Liu, F.; Traoré, B.; Katan, C.; Even, J.; Mohite, A. D.; Kanatzidis, M. G. High members of the 2D Ruddlesden-Popper halide perovskites: synthesis, optical properties, and solar cells of $\left(\mathrm{CH}_{3}\left(\mathrm{CH}_{2}\right)_{3} \mathrm{NH}_{3}\right)_{2}\left(\mathrm{CH}_{3} \mathrm{NH}_{3}\right)_{4} \mathrm{~Pb}_{5} \mathrm{I}_{16}$. Chem. 2017, 2, 427-440.

(42) Tsai, H.; Nie, W.; Blancon, J.-C.; Stoumpos, C. C.; Asadpour, R.; Harutyunyan, B.; Neukirch, A. J.; Verduzco, R.; Crochet, J. J.; Tretiak, S.; Pedesseau, L.; Even, J.; Alam, M. A.; Gupta, G.; Lou, J.; Ajayan, P. M.; Bedzyk, M. J.; Kanatzidis, M. G.; Mohite, A. D. Highefficiency two-dimensional Ruddlesden-Popper perovskite solar cells. Nature 2016, 536, 312-316.

(43) Ahn, N.; Son, D.-Y.; Jang, I.-H.; Kang, S. M.; Choi, M.; Park, N.G. Highly reproducible perovskite solar cells with average efficiency of $18.3 \%$ and best efficiency of $19.7 \%$ fabricated via Lewis base adduct of lead (II) iodide. J. Am. Chem. Soc. 2015, 137, 8696-8699.

(44) Yang, W. S.; Noh, J. H.; Jeon, N. J.; Kim, Y. C.; Ryu, S.; Seo, J.; Seok, S. I. High-performance photovoltaic perovskite layers fabricated through intramolecular exchange. Science 2015, 348, 1234-1237.

(45) NREL Chart; http://www.nrel.gov/pv/assets/images/ efficiency chart.jpg (accessed 05.01.2017).

(46) Wang, Z.; Shi, Z.; Li, T.; Chen, Y.; Huang, W. Stability of perovskite solar cells: a prospective on the substitution of the A cation and X anion. Angew. Chem., Int. Ed. 2017, 56, 1190-1212.

(47) Ishihara, T. Optical properties of PbI-based perovskite structures. J. Lumin. 1994, 60-61, 269-274.
(48) Smith, I. C.; Hoke, E. T.; Solis-Ibarra, D.; McGehee, M. D.; Karunadasa, H. I. A layered hybrid perovskite solar-cell absorber with enhanced moisture stability. Angew. Chem., Int. Ed. 2014, 53, 1123211235

(49) Russell, V. A.; Ward, M. D. Molecular crystals with dimensionally controlled hydrogen-bonded nanostructures. Chem. Mater. 1996, 8, 1654-1666.

(50) Russell, V. A.; Evans, C. C.; Li, W.; Ward, M. D. Nanoporous molecular sandwiches: pillared two-dimensional hydrogen-bonded networks with adjustable porosity. Science 1997, 276, 575-579.

(51) Pauling, L. The nature of the chemical bond and the structure of molecules and crystals; Cornell University Press: Ithaca, NY, 1940; pp 286-288.

(52) Hu, K.-L.; Kurmoo, M.; Wang, Z.; Gao, S. Metal-organic perovskites: synthesis, structures, and magnetic properties of [C$\left.\left(\mathrm{NH}_{2}\right)_{3}\right]\left[\mathrm{MII}(\mathrm{HCOO})_{3}\right] \quad(\mathrm{M}=\mathrm{Mn}, \mathrm{Fe}, \mathrm{Co}, \mathrm{Ni}, \mathrm{Cu}$, and $\mathrm{Zn}$; $\mathrm{C}\left(\mathrm{NH}_{2}\right)_{3}=$ Guanidinium). Chem. - Eur. J. 2009, 15, 12050-12064.

(53) Collings, I. E.; Hill, J. A.; Cairns, A. B.; Cooper, R. I.; Thompson, A. L.; Parker, J. E.; Tang, C. C.; Goodwin, A. L. Compositional dependence of anomalous thermal expansion in perovskite-like $\mathrm{ABX}_{3}$ formates. Dalton Trans. 2016, 45, 4169-4178.

(54) Szafrański, M.; Katrusiak, A. Phase transitions in the layered structure of diguanidinium tetraiodoplumbate. Phys. Rev. B: Condens. Matter Mater. Phys. 2000, 61, 1026-1035.

(55) Daub, M.; Haber, C.; Hillebrecht, H. Synthesis, crystal structures, optical properties and phase transitions of the layered guanidinium-based hybrid perovskites $\left(\mathrm{C}\left(\mathrm{NH}_{2}\right)_{3}\right)_{2} \mathrm{MI}_{4} ; \mathrm{M}=\mathrm{Sn}, \mathrm{Pb}$. Eur. J. Inorg. Chem. 2017, 2017, 1120-1126.

(56) Kieslich, G.; Sun, S.; Cheetham, A. K. Solid-state principles applied to organic-inorganic perovskites: new tricks for an old dog. Chem. Sci. 2014, 5, 4712-4715.

(57) Saba, M.; Cadelano, M.; Marongiu, D.; Chen, F.; Sarritzu, V.; Sestu, N.; Figus, C.; Aresti, M.; Piras, R.; Geddo Lehmann, A.; Cannas, C.; Musinu, A.; Quochi, F.; Mura, A.; Bongiovanni, G. Correlated electron-hole plasma in organometal perovskites. Nat. Commun. 2014, 5, 5049.

(58) Elliott, R. J. Intensity of optical absorption by excitons. Phys. Rev. 1957, 108, 1384-1389.

(59) Delley, B. An all-electron numerical method for solving the local density functional for polyatomic molecules. J. Chem. Phys. 1990, 92, 508-517.

(60) Delley, B. From molecules to solids with the DMol3 approach. J. Chem. Phys. 2000, 113, 7756-7764.

(61) Savin, A.; Nesper, R.; Wengert, S.; Fässler, T. F. ELF: the electron localization function. Angew. Chem., Int. Ed. Engl. 1997, 36, $1808-1832$.

(62) Max-Planck-Institut für Chemische Physik fester Stoffe; http:// www2.cpfs.mpg.de/ELF/.

(63) Weidman, M. C.; Seitz, M.; Stranks, S. D.; Tisdale, W. A. Highly tunable colloidal perovskite nanoplatelets through variable cation, metal, and halide composition. ACS Nano 2016, 10, 7830-7839.

(64) Hatch, D. M.; Stokes, H. T.; Aleksandrov, K. S.; Misyul, S. V. Phase transitions in the perovskitelike $\mathrm{A}_{2} \mathrm{BX}_{4}$ structure. Phys. Rev. B: Condens. Matter Mater. Phys. 1989, 39, 9282-9288.

(65) Trots, D. M.; Myagkota, S. V. High-temperature structural evolution of caesium and rubidium triiodoplumbates. J. Phys. Chem. Solids 2008, 69, 2520-2526.

(66) Moller, C. K. Crystal structure and photoconductivity of caesium plumbohalides. Nature 1958, 182, 1436-1436.

(67) Rodová, M.; Brožek, J.; Knížek, K.; Nitsch, K. Phase transitions in ternary caesium lead bromide. J. Therm. Anal. Calorim. 2003, 71, $667-673$.

(68) Kawano, N.; Koshimizu, M.; Sun, Y.; Yahaba, N.; Fujimoto, Y.; Yanagida, T.; Asai, K. Effects of organic moieties on luminescence properties of organic-inorganic layered perovskite-type compounds. J. Phys. Chem. C 2014, 118, 9101-9106.

(69) Tanaka, K.; Takahashi, T.; Kondo, T.; Umeda, K.; Ema, K.; Umebayashi, T.; Asai, K.; Uchida, K.; Miura, N. Electronic and excitonic structures of inorganic-organic perovskite-type quantum- 
well crystal $\left(\mathrm{C}_{4} \mathrm{H}_{9} \mathrm{NH}_{3}\right)_{2} \mathrm{PbBr}_{4}$. Jpn. J. Appl. Phys. 2005, 44, 59235932.

(70) Cola, M.; Massarotti, V.; Riccardi, R.; Sinistri, C. Binary systems formed by lead bromide with ( $\mathrm{Li}, \mathrm{Na}, \mathrm{K}, \mathrm{Rb}, \mathrm{Cs}$ and $\mathrm{Tl}$ ) $\mathrm{Br}$ : a DTA and diffractometric study. Z. Naturforsch., A: Phys. Sci. 1971, 26, 13281332.

(71) Szafrański, M. Thermochim. Acta 1997, 307, 177-183.

(72) Dong, Q.; Fang, Y.; Shao, Y.; Mulligan, P.; Qiu, J.; Cao, L.; Huang, J. Electron-hole diffusion lengths $>175 \mu \mathrm{m}$ in solution-grown $\mathrm{CH}_{3} \mathrm{NH}_{3} \mathrm{PbI}_{3}$ single crystals. Science 2015, 347, 967-970.

(73) Saidaminov, M. I.; Almutlaq, J.; Sarmah, S.; Dursun, I.; Zhumekenov, A. A.; Begum, R.; Pan, J.; Cho, N.; Mohammed, O. F.; Bakr, O. M. Pure $\mathrm{Cs}_{4} \mathrm{PbBr}_{6}$ : highly luminescent zero-dimensional perovskite solids. ACS Energy Lett. 2016, 1, 840-845.

(74) Szafrański, M.; Ståhl, K. Pressure-induced decoupling of the order-disorder and displacive contributions to the phase transition in diguanidinium tetrachlorostannate. Phys. Rev. B: Condens. Matter Mater. Phys. 2000, 62, 8787-8793.

(75) Knutson, J. L.; Martin, J. D.; Mitzi, D. B. Tuning the band gap in hybrid tin iodide perovskite semiconductors using structural templating. Inorg. Chem. 2005, 44, 4699-4705.

(76) Smith, M. D.; Jaffe, A.; Dohner, E. R.; Lindenberg, A. M.; Karunadasa, H. I. Structural origins of broadband emission from layered $\mathrm{Pb}-\mathrm{Br}$ hybrid perovskites. Chem. Sci. 2017, 8, 4497-4504.

(77) Yangui, A.; Garrot, D.; Lauret, J. S.; Lusson, A.; Bouchez, G.; Deleporte, E.; Pillet, S.; Bendeif, E. E.; Castro, M.; Triki, S.; Abid, Y.; Boukheddaden, $\mathrm{K}$. Optical investigation of broadband white-light emission in self-assembled organic-inorganic perovskite $\left(\mathrm{C}_{6} \mathrm{H}_{11} \mathrm{NH}_{3}\right)_{2} \mathrm{PbBr}_{4}$. J. Phys. Chem. C 2015, 119, 23638-23647.

(78) Bakulin, A. A.; Selig, O.; Bakker, H. J.; Rezus, Y. L. A.; Müller, C.; Glaser, T.; Lovrincic, R.; Sun, Z.; Chen, Z.; Walsh, A.; Frost, J. M.; Jansen, T. L. C. Real-time observation of organic cation reorientation in methylammonium lead iodide perovskites. J. Phys. Chem. Lett. 2015, 6, 3663-3669.

(79) Dirin, D. N.; Cherniukh, I.; Yakunin, S.; Shynkarenko, Y.; Kovalenko, M. V. Solution-grown $\mathrm{CsPBr}_{3}$ perovskite single crystals for photon detection. Chem. Mater. 2016, 28, 8470-8474.

(80) Saliba, M.; Matsui, T.; Domanski, K.; Seo, J.-Y.; Ummadisingu, A.; Zakeeruddin, S. M.; Correa-Baena, J.-P.; Tress, W. R.; Abate, A.; Hagfeldt, A.; Grätzel, M. Incorporation of rubidium cations into perovskite solar cells improves photovoltaic performance. Science 2016, 354, 206-209.

(81) Hou, X.; Hu, Y.; Liu, H.; Mei, A.; Li, X.; Duan, M.; Zhang, G.; Rong, Y.; Han, H. Effect of guanidinium on mesoscopic perovskite solar cells. J. Mater. Chem. A 2017, 5, 73-78.

(82) Marco, N. D.; Zhou, H.; Chen, Q.; Sun, P.; Liu, Z.; Meng, L.; Yao, E.-P.; Liu, Y.; Schiffer, A.; Yang, Y. Guanidinium: a route to enhanced carrier lifetime and open-circuit voltage in hybrid perovskite solar cells. Nano Lett. 2016, 16, 1009-1016. 